\title{
Reinstatement of Perinereis bairdii (Webster, 1884) and description of $P$. websteri sp. nov. from Bermuda, including the reproductive morphology of two Atlantic Perinereis species (Annelida: Errantia: Phyllodocida)
}

\author{
Víctor Manuel CONDE-VELA ${ }^{\oplus 1,2}$ \\ ${ }^{1}$ Facultad de Ciencias Biológicas, Universidad Autónoma de Nuevo León, \\ San Nicolás de Los Garza, Mexico. \\ ${ }^{2}$ El Colegio de la Frontera Sur, Departamento de Ecología Acuática, Chetumal, \\ Quintana Roo 77010, Mexico. \\ Email: victorconde2323@gmail.com \\ urn:1sid:zoobank.org:author:44DFD70C-BA95-46B1-B12D-0E9D800D024A
}

\begin{abstract}
Perinereis anderssoni Kinberg, 1865 originally described from Brazil has been attributed with a wide distribution on the American Atlantic coasts, ranging from Brazil to Bermuda, due to the synonymy of Nereis bairdii Webster, 1884 and Nereis (Perinereis) melanocephala McIntosh, 1885. In this paper, the synonymy of Nereis bairdii with Perinereis anderssoni is rejected based on a reexamination of the syntypes of $N$. bairdii which are found to contain two species requiring designation of a lectotype and paralectotypes here redescribed as Perinereis bairdii (Webster, 1884) and the remaining specimens are here described as Perinereis websteri sp. nov. The synonymy of Nereis (Perinereis) melanocephala with $P$. anderssoni is rejected and the synonymy with $P$. bairdii proposed by previous authors is accepted here. A description of $P$. anderssoni, a redescription of $P$. floridana, and a description of the males of $P$. cariboea with additional material are provided for comparison. A key to identifying all Atlantic Perinereis species is also included.
\end{abstract}

Keywords. Lectotype designation, epitoky, pharyngeal regions, oral ring, taxonomy.

Conde-Vela V.M. 2022. Reinstatement of Perinereis bairdii (Webster, 1884) and description of P. websteri sp. nov. from Bermuda, including the reproductive morphology of two Atlantic Perinereis species (Annelida: Errantia: Phyllodocida). European Journal of Taxonomy 787: 104-145. https://doi.org/10.5852/ejt.2021.787.1619

\section{Introduction}

The genus Perinereis Kinberg, 1865 is one of the largest genera among nereidids (Villalobos-Guerrero et al. 2021) and considered polyphyletic because it groups species with a high heterogeneous morphology (Bakken \& Wilson 2005), which leads to the use of informal groups based on the number of smooth bars in the areas VI of the pharynx and the relative size of dorsal ligules in posterior chaetigers (Hutchings et al. 1991). Also, Perinereis has several sympatric species with a high morphological similarity, 
although they are recognized only after detailed morphological, phylogeographic, or molecular studies (e.g., Glasby \& Hsieh 2006; Paiva et al. 2018; Tosuji et al. 2019).

Therefore, it is reasonable to think that some Perinereis species with a wide associated morphological variation represent two or more sympatric species, as in the case of Nereis bairdii Webster, 1884, a current junior synonym of Perinereis anderssoni Kinberg, 1865. In his original description, Webster (1884) stated N. bairdii had long or short tentacular cirri and dorsal ligules with similar size along the body or increasing their size toward posterior chaetigers, raising some doubts about whether there are two species instead of just one. Treadwell $(1901,1939)$ also recognized two morphological patterns in some specimens from Puerto Rico and identified as Nereis bairdii: 1) some specimens with darker brown pigment in the anterior region with white spots on brown bands in the prostomium and the chaetigers, and with short tentacular cirri and 'well developed' dorsal ligules in posterior chaetigers; and 2) the other specimens with brown pigment but less distributed and lacking white spots on prostomium and segments, and with long tentacular cirri, and 'less developed' dorsal ligules. Despite these differences, Treadwell thought that they were just two varieties of the same species, $N$. bairdii. The name Nereis bairdii was scarcely reported for the Caribbean Sea (e.g., Hoagland 1919; Augener 1927, 1936), Monro (1933b) transferred the species to Perinereis, and later Hartman $(1944,1948)$ subjectively synonymized Nereis bairdii with Perinereis anderssoni Kinberg, 1865, widening the range of both morphological and geographic distribution of the latter species, which was followed since then.

To assess the validity of the synonymy of Nereis bairdii with Perinereis anderssoni, the syntypes of the former species were examined, finding that the syntypes can be grouped into two distinct morphological patterns: specimens having tentacular cirri reaching up to chaetiger 2 and several paragnaths in areas VIIVIII arranged into two bands, and specimens having tentacular cirri reaching chaetiger 8 and paragnaths less numerous and in one band. This problem is solved by splitting the type series and designating a lectotype and paralectotypes for $N$. bairdii and then determining if they are distinct from P. anderssoni, and later evaluating if the remaining specimens belong to $P$. anderssoni or another described or perhaps undescribed species. However, the situation is complicated since the original description mixed features from both morphological patterns, making it difficult to decide which specimens should be designated as the type material bearing the name Nereis bairdii.

Therefore, the main objectives of the present paper are 1) the redescription of Nereis bairdii with the split of the syntypes and designation of lectotype and paralectotypes; 2 ) the description of a new species of Perinereis from Bermuda based on some of the syntypes of $N$. bairdii and additional material; 3 ) the re-evaluation of the synonymy of $N$. bairdii with $P$. anderssoni by comparison of topotypes of the latter species; and 4) the description of the reproductive morphology of the similar species Perinereis floridana (Ehlers, 1868) and P. cariboea de León-González \& Solís-Weiss, 1998, and comparison with N. bairdii.

\section{Material and methods}

Specimens are deposited in the following institutions:

$\begin{aligned} \text { ECOSUR }= & \text { El Colegio de la Frontera Sur, Unidad Chetumal, Mexico } \\ \text { LACM-AHF = } & \text { Natural History Museum of Los Angeles County, Allan Hancock Foundation, Los } \\ & \text { Angeles, California, USA } \\ = & \text { Museum of Comparative Zoology, Harvard University, Massachusetts, USA } \\ \text { MCZ } & \text { National Museum of Natural History, Smithsonian Institution, Washington D.C., } \\ \text { USNM } & \text { USA }\end{aligned}$


For comparison, specimens of Perinereis rookeri (LACM-AHF 4998, paratype, Rookery Bay; USNM 24526, non-type, Bimini Island) and P. cariboea (USNM 180694, holotype, Quintana Roo), were examined.

Specimens were examined with a stereo microscope and compound microscopes. Some parapodia were removed along the body and mounted on semi-permanent slides with ethanol-glycerol, and examined under the compound microscope. Photographs were taken with a Sony Alpha-6000 camera with an adaptor for both microscopes. All parapodia are shown in anterior view. To improve the depth of the visual field of figures, a set of photographs was digitally stacked with Zerene Stacker and further processed with Adobe Photoshop.

When available, the number of paragnaths of holotype/lectotype is mentioned first in the descriptions, followed by the range of variation in paratypes/paralectotypes and additional material in parentheses. For describing parapodia of atoke and epitoke specimens, Villalobos-Guerrero \& Bakken (2018) and Conde-Vela et al. (2018) terminologies were followed, and Conde-Vela (2018) and Villalobos-Guerrero (2019) were followed for describing pharyngeal characteristics. The proposal of Conde-Vela (2018) for
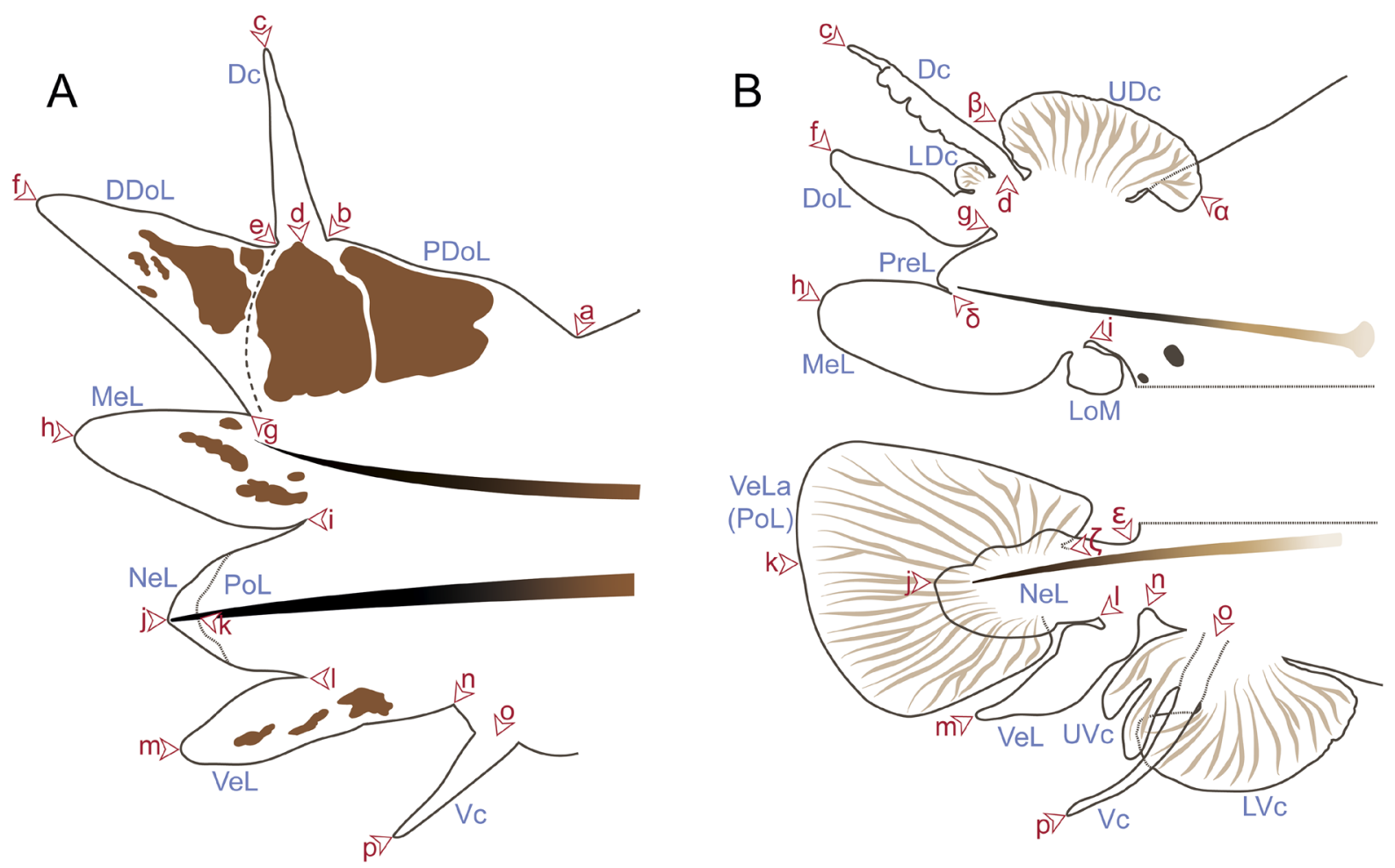

Fig. 1. Parapodial morphology of species of Perinereis Kinberg, 1865 and points used to obtain segments and length ratios of parapodial structures described in this work. Arrows and labels correspond to points used for the measuring parapodial structures as described in Material and methods section. A. Parapodium from posterior chaetiger of Perinereis floridana (Ehlers, 1868) (ECOSUR P1100). B. Parapodium from natatory region of Perinereis floridana (LACM-AHF 7376). Abbreviations: Dc $=$ dorsal cirrus; $\mathrm{DDoL}=$ distal lobe of dorsal ligule; $\mathrm{DoL}=$ dorsal ligule; $\mathrm{LDc}=$ lower lamella of dorsal cirrus; $\mathrm{LoM}=$ lower lamella of median ligule; $\mathrm{LVc}=$ lower lamella of ventral cirrus; $\mathrm{MeL}=$ median ligule; $\mathrm{NeL}=$ neuroacicular ligule; $\mathrm{PDoL}=$ proximal lobe of dorsal ligule; $\mathrm{PoL}=$ neuropodial postchaetal lobe; PreL = notopodial prechaetal lobe; UDc $=$ upper lamella of dorsal cirrus; UVc $=$ upper lamella of ventral cirrus; $\mathrm{Vc}=$ ventral cirrus; $\mathrm{VeL}=$ ventral ligule; $\mathrm{VeLa}=$ ventral lamella. 
determining the position and number of bands and rows was used, and it was improved to depict all the oral ring to show the areas VI-V-VI pattern and the position and relative size of bars in areas V and VI, facilitating the interpretation of the paragnaths patterns in the oral ring. For describing chaetal shafts and parapodial structures, Conde-Vela (2021) was followed and adapted for including proximal and distal lobes of dorsal ligules (Villalobos-Guerrero 2019) and measures for epitokous parapodia; here, the lobe at the dorsal surface of dorsal ligules in natatory chaetigers are interpreted as the lower lamella of dorsal cirrus instead of an "upper secondary lobe of distal dorsal ligule" (Villalobos-Guerrero et al. 2021) because its morphology closely resembles to the upper lamella of dorsal cirrus.

Points for measures were placed as described by Conde-Vela (2021) and are depicted as in Figure 1; the segments for the ratios were obtained as follows: $\mathrm{Dc} / \mathrm{PDoL}=\mathrm{cd} / \mathrm{ab} ; \mathrm{Dc} / \mathrm{DDoL}=\mathrm{cd} / \mathrm{ef} ; \mathrm{UDc} / \mathrm{Dc}=\alpha \beta /$ cd; DDoL $/ \mathrm{MeL}=$ fg/gh; DoL/MeL = fg/ $/ \mathrm{h} ; \mathrm{MeL} / \mathrm{NeL}=\mathrm{hi} / \mathrm{ij}$ or $\mathrm{MeL} / \mathrm{NeL}=\mathrm{hi} / \varepsilon \mathrm{j} ; \mathrm{NeL} / \mathrm{VeL}=\mathrm{jl} / \mathrm{lm} ; \mathrm{PoL} /$ $\mathrm{NeL}=\mathrm{ik} / \mathrm{ij}$ or $\mathrm{VeLa} / \mathrm{NeL}=\zeta \mathrm{k} / \varepsilon \mathrm{j} ; \mathrm{VeL} / \mathrm{NeL}=\mathrm{lm} / \mathrm{jl} ; \mathrm{VeL} / \mathrm{Vc}=\mathrm{mn} / \mathrm{op} ; \mathrm{Vc} / \mathrm{VeL}=\mathrm{op} / \mathrm{mn}$.

\section{Results}

\section{Taxonomy}

Phylum Annelida Lamarck, 1809

Class Polychaeta Grube, 1850

Order Phyllodocida Dales, 1962

Family Nereididae de Blainville, 1818

Genus Perinereis Kinberg, 1865

Perinereis anderssoni Kinberg, 1865

Figs 2, 13

Perinereis anderssoni Kinberg, 1865: 175.

Nereis minor Hansen, 1882: 12, pl. 4 figs 8-12.

Perinereis anderssoni-Hartman 1948: 72-73. — De León-González \& Solís-Weiss 1998: 675, figs 1a-g (partim).

\section{Material examined}

BRAZIL • 7 specs; Rio de Janeiro, Praia Vermelha; 16 Aug. 2012; M. Coutihno and V. Schawn leg.; ECOSUR P3208.

\section{Description}

BODY AND MEASUREMENTS. Non-type specimens (ECOSUR P3208) in good conditions, complete, largest specimen $23 \mathrm{~mm}$ long, $1.9 \mathrm{~mm}$ wide at chaetiger 10 excluding parapodia, 67 chaetigers. Body dorsally pigmented, with reddish brown pigmentation in palps, prostomium and chaetigers, intense in anterior region, progressively discoloring posteriorly (Fig. 2A-B). Pale lines present in dorsum of first 12 chaetigers (Fig. 2A), fingerprint-like pattern from chaetiger 13.

Prostomium. Subpyriform, as long as wide; anterior region distally entire, rectangular, slightly longer than posterior region, dorsal groove present (Fig. 2A); anterolateral gap between antenna and palpophore as long as diameter of antennae.

Antennae. Digitiform, not passing palps, lacking pigments, half as long as prostomium, gap between them as long as basal wide of antennae (Fig. 2A). 
PALPS. Palpophores ovoid, swollen, $1.5 \times$ as long as wide, shorter than prostomium, subdistal transverse groove present (Fig. 2A). Palpostyles rounded.

EYES. Rounded, anterior and posterior pairs subequal, in trapezoidal arrangement, posterior pair covered by anterior margin of tentacular belt (Fig. 2A).

TENTACULAR BeLt. $1.5 \times$ as long as chaetiger 1 , covering posterior pair of eyes, anterior dorsal margin straight (Fig. 2A).

Tentacular CiRri. Moniliform, not jointed, basal segment largest, remaining ones decrease in size progressively toward distal end longest cirri reaching end of chaetiger 1 (Fig. 2A).

Pharynx. Dissected; jaws brown, cutting edge with 10 rounded teeth (Fig. 2D). Maxillary ring: I = 5 cones in triangle; II $=11-12$ cones in arc; III $=19$ cones in rectangle; IV $=19-33$ cones in arc. Oral ring: $\mathrm{V}=3$ cones in triangle, two cones over each lateral edges; VI $=1-1$ smooth bars; VII-VIII $=$ 40 cones in two bands: anterior band with 8 paragnaths in a furrow row with 1 cone on the regions a-d, and 12 paragnaths in ridge row with 1 cone on each $\mathrm{B}-\mathrm{G}$ regions; posterior band with 8 paragnaths in furrow row with 1 cone on the regions a-d, and 12 paragnaths in ridge row with 2 cones on region $\mathrm{A}$ and 1 cone on the regions B-F (Fig. 13). Furrow pattern of areas VI-V-VI, П-shaped (Fig. 13).

DORSAL CIRRI. Digitiform in first chaetigers, filiform thereafter, attached basally to dorsal ligule in anteriormost chaetigers, medially in middle chaetigers, and subdistally in posterior chaetigers (Fig. 2EI); $1.5 \times$ as long as distal lobe of dorsal ligule in chaetiger $1,2.2 \times$ in chaetiger $10,2.3 \times$ in chaetiger 28 , $2.5 \times$ in chaetiger $45,3.2 \times$ in chaetiger 62 (Fig. $2 \mathrm{E}-\mathrm{I}$ ); $4.7 \times$ as long as proximal lobe of dorsal ligule in chaetiger $1,2.7 \times$ in chaetiger $10,2.6 \times$ in chaetiger $28,1.5 \times$ in chaetiger $45,1 \times$ length in chaetiger 62 (Fig. 2E-I).

Dorsal Ligules. Subconical with blunt tip in anterior and middle chaetigers, becoming pennant-like toward posterior chaetigers, with distal lobes longer than proximal ones in first chaetigers, becoming as long as in anterior and shorter than in middle and posterior chaetigers (Fig. 2E-I). Distal lobe of dorsal ligule subconical throughout; as long as median ligule in chaetigers 10 and 28, 1.8 $\times$ as long as in chaetiger 45, $2.8 \times$ in chaetiger 62 (Fig. 2E-I).

Median Ligules. Subconical with blunt tip in anterior chaetigers, becoming sharper thereafter (Fig. 2EI); $1 \times$ length of neuroacicular ligule in chaetiger $10,4.3 \times$ in chaetiger $28,2 \times$ in chaetigers 45 and 62 (Fig. 2E-I).

Neuroacicular ligules. Subconical in anterior and middle chaetigers, becoming rounded in posterior ones (Fig. $2 \mathrm{E}-\mathrm{I}$ ); $0.7 \times$ length of ventral ligule in chaetiger $1,2 \times$ in chaetiger $10,1 \times$ in chaetiger $28,2 \times$ in $45,1.6 \times$ in chaetiger 62 (Fig. $2 \mathrm{E}-\mathrm{I}$ ).

NeUROPOdial SUPERIOR AND INFERIOR LOBES. Present in anterior and middle chaetigers, both rounded, inferior one wider than superior one throughout (Fig. 2E-I).

Neuropodial postchaetal Lobes. Rounded, half as long as neuroacicular ligule throughout.

Ventral Ligules. Digitiform throughout (Fig. 2E-I).

Ventral CiRRI. Digitiform throughout (Fig. 2E-I); $1 \times$ length of ventral ligule in chaetiger $1,0.8 \times$ length thereafter (Fig. 2E-I).

ACiCULAE. Dark brown throughout (Fig. 2A-I); notoaciculae absent in first two chaetigers (Fig. 2E). 
NotochaеtaE. All homogomph symmetrical spinigers. Blades of spinigers with basal pectinate, coarse teeth, becoming minute toward distal end.

NEUROCHAETAE. Homogomph symmetrical spinigers and heterogomph falcigers in supra-acicular fascicles, heterogomph spinigers and falcigers in sub-acicular fascicles. Neuropodial homogomph spiniger as notopodial ones. Heterogomph spinigers with blades pectinate, minute teeth and decreasing in size toward distal end. Heterogomph falcigers pectinate, long and narrow teeth, half of inner edge of blade dentate, distal tips stout, stouter in supra-acicular falcigers (Fig. 2J-K).

Pygidium. Crenulated, bilobate (Fig. 2B); anal cirri subulate, as long as last three chaetigers (Fig. 2B).

\section{Remarks}

Kinberg (1865) included few features in the original description of $P$. anderssoni, all focused on features of the anterior end of the body. Hartman (1948) briefly redescribed the species and regarded Nereis bairdii Webster, 1884, and doubtfully P. ponteni Kinberg, 1865, as junior synonyms. Morphological differences between P. anderssoni and P. ponteni have been pointed out in recent studies (e.g., Coutinho \& Santos 2014; Coutinho et al. 2015), and here the synonymy of $N$. bairdii is rejected (see remarks of Perinereis bairdii below). Epitokes were not available for this study, but recently Peixoto \& Santos (2016) detailed the reproductive biology of $P$. anderssoni, finding four epitokal stages in both males and females.

De León-González \& Solís-Weiss (1998) redescribed P. anderssoni based on the best-preserved specimen of the syntype series, but they highlighted the poor conditions of the type series and the absence of pigmentation. To improve the available redescription, a complementary description is provided based on topotypes in better condition of preservation. De León-González \& Solís-Weiss (1998) also recorded the species from Chile and the Gulf of Mexico, regarding it as amphiamerican. The inclusion of material from Juan Fernández, Chile is explained after Hartman (1948) noted some similarities in parapodia between P. anderssoni and P. pseudocamiguina (Augener, 1922) (type locality: Juan Fernández) (Augener 1922; Hutchings et al. 1991), but there are differences between them: 1) P. pseudocamiguina has 1-2 cones in area I, 7-13 cones in area III, and occasionally bars in areas IV; whereas $P$. anderssoni has $4-5$ cones in area I, 19-21 cones in areas III, and no bars in areas IV; 2) in P. pseudocamiguina, dorsal cirri in posterior chaetigers are $0.5-0.6 \times$ as long as proximal lobe of dorsal ligule, whereas in $P$. anderssoni they ate as long as; 3 ) in P. pseudocamiguina, dorsal cirri are $2.0-2.2 \times$ as long as distal lobe of dorsal ligules, whereas in $P$. anderssoni they are $3.2 \times$ longer; 4 ) in $P$. pseudocamiguina, the dorsal ligules in posterior chaetigers are longer than wide and with dorsal surface slightly convex; whereas in $P$. anderssoni, they are wider than long and with dorsal surface strongly convex. Finally, Hartman (1948), following Augener (1934), also considered N. minor Hansen, 1882 (type locality: Rio de Janeiro, Brazil) as a probable junior synonym of $P$. anderssoni; the original description is succinct, but the illustrations included show the high similarities in the arrangement of paragnaths and the parapodia (probably from anterior chaetigers), so the synonymy with $N$. minor is retained until a further revision of type material.

Liñero-Arana \& Reyes-Vásquez (1979) reported P. anderssoni from Venezuela, but based on the redescription and the current description, there are key differences between Venezuelan specimens and P. anderssoni: 1) in Venezuelan specimens, numbers of paragnaths in some pharyngeal areas as follows: $\mathrm{I}=10-18, \mathrm{II}=20-27, \mathrm{~V}=1$, whereas in $P$. anderssoni are as follows: $\mathrm{I}=5, \mathrm{II}=11-12, \mathrm{~V}=3 ; 2$ ) in Venezuelan specimens, dorsal cirri in posterior chaetigers are $0.6 \times$ as long as proximal lobes and $1.5 \times$ as long as distal lobes of dorsal ligules, whereas in P. anderssoni, dorsal cirri are as long as proximal lobes and $3.2 \times$ as long as distal lobes of dorsal ligules; 3 ) in Venezuelan specimens, the dorsal ligules are at least $3.5 \times$ as long as median ligules and the ventral ligules are $2-4 \times$ longer than neuroacicular ligules in posterior chaetigers, whereas in P. anderssoni, the dorsal ligules are $2.8 \times$ as long as median ligules and ventral ligules are shorter than neuroacicular ligules. These specimens are closer to P. ponteni 
or $P$. bairdii than to $P$. anderssoni because of the large number of paragnaths in area I and a single paragnath in area V, recorded a couple of times (Díaz-Díaz \& Liñero-Arana 2002; Vanegas-Espinosa et al. 2007). The two Perinereis species described from Venezuela, P. mochimaensis Liñero-Arana, 1983 and $P$. cariacoensis Liñero-Arana, 1983, are also different, therefore Venezuelan specimens belong to another, undescribed species.

Following Hartman (1948), Rioja (1960) reported P. anderssoni for Veracruz, Mexico but recognizing that the specimens are closer to $P$. ponteni. Key differences among these Mexican specimens and
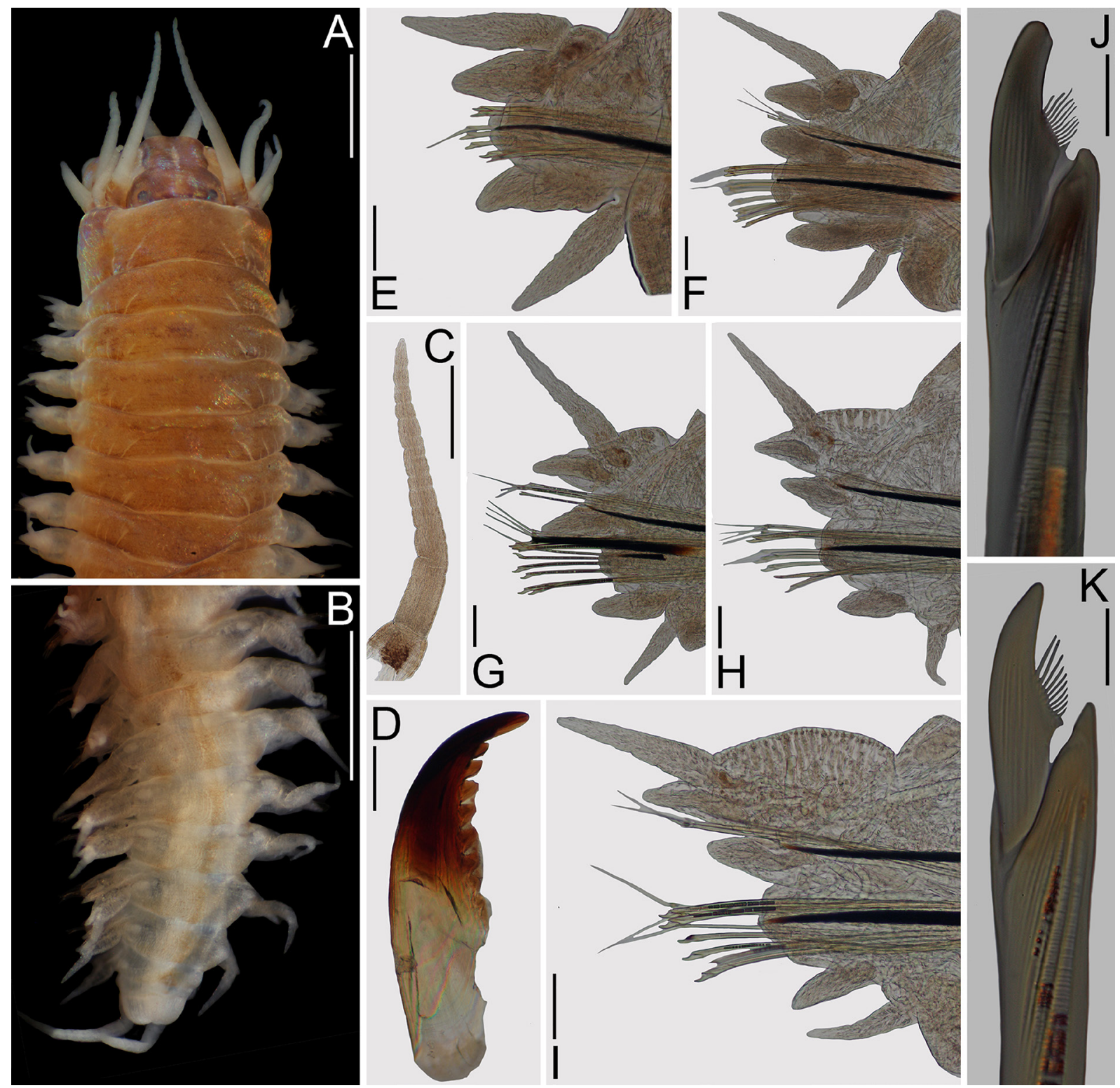

Fig. 2. Perinereis anderssoni Kinberg, 1865. Topotype (ECOSUR P3208). A. Anterior end, dorsal view. B. Posterior end, dorsal view. C. Posterodorsal tentacular cirri. D. Left jaw, dorsal view. E. Chaetiger 1, right parapodium. F. Chaetiger 10, right parapodium. G. Chaetiger 28, right parapodium. H. Chaetiger 45, right parapodium. I. Chaetiger 62, right parapodium. J. Supra-acicular heterogomph falciger, chaetiger 62 . K. Sub-acicular heterogomph falciger, chaetiger 28 . Scale bars: A-C $=1 \mathrm{~mm} ; \mathrm{D}=$ $0.25 \mathrm{~mm} ; \mathrm{E}-\mathrm{I}=0.1 \mathrm{~mm} ; \mathrm{J}-\mathrm{K}=10 \mu \mathrm{m}$. 
P. anderssoni are the following: 1) in Mexican specimens, area I has 10-12 cones and area $\mathrm{V}$ has 1 cone, whereas in $P$. anderssoni, area I has 5 cones and area $V$ has 3 cones; 2) in Mexican specimens, antennae are $0.3 \times$ as long as prostomium, whereas in $P$. anderssoni they are half as long; 3 ) in Mexican specimens, dorsal cirri in anterior chaetigers are shorter than distal lobes of dorsal ligules, whereas in $P$. anderssoni they are longer; 4 ) in Mexican specimens, dorsal cirri are $2 \times$ as long as distal lobes of dorsal ligules and ventral ligules are $2.5 \times$ as long as neuroacicular ligules in posterior chaetigers, whereas in P. anderssoni dorsal cirri are $3.2 \times$ longer and the ventral ligules are shorter than. Salazar-Vallejo \& Jiménez-Cueto (1997) reported P. anderssoni for the Mexican Caribbean, but these specimens differ from Brazilian ones in the following features: 1 ) in the Caribbean specimens, dorsal cirri are $1.4 \times$ as long as distal lobes of dorsal ligules and median ligules are as long as neuroacicular ligules in anterior chaetigers, whereas in the Brazilian ones the dorsal cirri are $2.2 \times$ longer and median ligules are subequal; 2 ) in the Caribbean specimens, dorsal cirri are $0.5 \times$ as long as proximal lobes and as long as distal lobes of dorsal ligules in posterior chaetigers, whereas in the Brazilian ones the dorsal cirri are as long as proximal lobes and $3.2 \times$ as long as distal lobes. Records of P. anderssoni in other Caribbean regions (e.g., Fauchald 1977; Ibárzabal 1986) deserve a new evaluation.

\section{Distribution}

Brazil.

Perinereis bairdii (Webster, 1884) reinstated

Figs 3-6, 13

Nereis bairdii Webster, 1884: 312-313, pl. 8 figs 22a-24, 25-26, 27-28.

Nereis (Perinereis) melanocephala McIntosh, 1885: 216-219, pl. 34 figs 14-17, pl. 16a figs 8-9.

Perinereis bairdii - Monro 1933b: 41 (synonym and new combination only).

\section{Type material}

Lectotype (hereby designated)

BERMUDA• 1 spec.; Bermuda; 1876; G.B. Goode leg.; USNM 4786.

Paralectotypes (hereby designated)

BERMUDA • 4 specs; Bermuda; 1876; G.B. Goode leg.; USNM 1660576.

\section{Additional material}

BERMUDA • 1 spec.; Bermuda, SW of Whalebone Bay; 17 Nov. 1979; M.L. Jones leg.; USNM 1480190

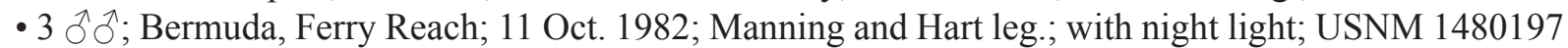

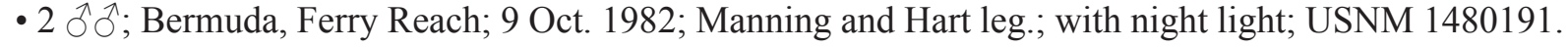

\section{Description}

\section{Atoke}

Body AND MEASUREMENTS. Specimen designated as lectotype (USNM 4786) complete, $26 \mathrm{~mm}$ long, 1.7 $\mathrm{mm}$ wide at chaetiger 10 excluding parapodia, 64 chaetigers (Fig. 3A-B). Specimens designated as paralectotypes (USNM 1660576) (Fig. 3D-F) 4 complete, in good condition, largest paralectotype 48 $\mathrm{mm}$ long, $2 \mathrm{~mm}$ wide at chaetiger 10 excluding parapodia, 118 chaetigers. Additional non-type specimen (USNM 1480190) complete, in excellent conditions, $50 \mathrm{~mm}$ long, $\mathrm{mm}$ wide at chaetiger 10 excluding parapodia, 77 chaetigers (Fig. 4A-B). Pigmentation faded out in type and additional specimens. 
Prostomium. Subpyriform, as long as wide, anterior region distally entire, as long as posterior region, dorsal groove present (Figs 3A, 4A); anterolateral gap between antenna and palpophore as long as diameter of antennae (Figs 3A, 4A).

Antennae. Digitiform or subconical, not passing palps, $0.3 \times$ as long as prostomium, gap between them as long as basal wide of antennae (Figs 3A, 4A).

PALPS. Palpophores subconical, swollen, $1.2 \times$ as long as wide, shorter than prostomium, subdistal transverse groove present (Figs 3A, F, 4A). Palpostyles rounded or digitiform (Figs 3A, F, 4A).

EYEs. Rounded, anterior and posterior pairs subequal, in trapezoidal arrangement, sometimes posterior pair partly covered by anterior margin of tentacular belt (Figs 3A, 4A).

TENTACUlAR BeLt. 1.5-2.0 $\times$ as long as chaetiger 1, covering posterior pair of eyes, anterior dorsal margin straight and sometimes omega-shaped (Figs 3A, E-F, 4A).

Tentacular CirRi. Moniliform, not joint, basal segment largest, remaining ones decrease in size progressively toward distal end longest cirri reaching end of chaetigers 2-3 (Figs 3A, F, 4A).

Pharynx. Everted in both types and additional material; jaws brown, cutting edge with $8-11$ teeth (Figs 3D, 5E), proximal ones sometimes ensheathed (Fig. 4E). Maxillary ring: $\mathrm{I}=7$ cones in triangle (5-18); II = 15-16 cones in arc (11-28); III = 6 in ellipse (6-22); IV $=21-24$ cones in triangle (14-52) (Figs 3C, E-F). Oral ring: $\mathrm{V}=1$ cone $(0-1)$; VI $=1-1$ smooth bar $(1-1)$; VII-VIII $=39$ cones $(33-39)$ in two bands: anterior band with 10 paragnaths in furrow row with 1 cone on the regions a-e, and 11 paragnaths in ridge row with 1 cone on the regions $\mathrm{A}-\mathrm{F}$; posterior band with 18 paragnaths in a single ridge row with two cones on the regions A-E (Figs 3C, E-F, 13). Furrow pattern of areas VI-V-VI, $\lambda$-shaped (Figs 3A, 13).

DORSAL CIRRI. Digitiform in first chaetigers, subconical with blunt tip thereafter, attached basally to dorsal ligule in anteriormost chaetigers, medially in middle chaetigers, and subdistally in posterior chaetigers (Figs 3G-J, 4F-K); $1 \times$ length of distal lobe of dorsal ligule in chaetigers $1-2,1.2 \times$ as long as in chaetigers $10-34,1 \times$ in chaetigers $41-59,1.7 \times$ in chaetiger $72($ Figs $3 \mathrm{G}-\mathrm{J}, 4 \mathrm{~F}-\mathrm{K}$ ); $4 \times$ than proximal lobe of dorsal ligule in chaetigers $1-2,1.5 \times$ in chaetigers $10-11,1.2 \times$ in chaetigers $21-41,0.58 \times$ length in chaetigers $57-59,0.3 \times$ in chaetiger 72 (Figs $3 \mathrm{G}-\mathrm{J}, 4 \mathrm{~F}-\mathrm{K}$ ).

Dorsal Ligules. Subconical with blunt tip in anterior and middle chaetigers, becoming pennant-like toward posterior chaetigers, with distal lobes longer than proximal ones in first chaetigers, becoming as long as in anterior chaetigers, and shorter than in middle and posterior chaetigers (Figs $3 \mathrm{G}-\mathrm{J}, 4 \mathrm{~F}-\mathrm{K}$ ). Distal lobe of dorsal ligule lanceolate with blunt tip in anterior chaetigers, subconical thereafter; $1.6 \times$ as long as median ligule in chaetiger 10-11, $1.8 \times$ in chaetigers $21-41,3.4 \times$ length in chaetigers $57-59$, $3.3 \times$ in chaetiger 72 (Figs $3 \mathrm{G}-\mathrm{J}, 4 \mathrm{~F}-\mathrm{K}$ ).

Median Ligules. Digitiform in anterior chaetigers, becoming subconical with blunt tip thereafter (Figs 3G-J, 4F-K); $2.4 \times$ as long as neuroacicular ligule in chaetiger 10-11, 1.8 $\times$ in chaetiger 21-34, $1.5 \times$ in chaetiger $41,2.5 \times$ in chaetigers $57-59,1.8 \times$ in chaetiger 72 (Figs $3 \mathrm{G}-\mathrm{J}, 4 \mathrm{~F}-\mathrm{K}$ ).

Neuroacicular ligules. Subconical throughout (Figs 3G-J, 4F-K); $0.6 \times$ length of ventral ligule in chaetigers $1-2,1 \times$ in chaetigers $10-41,0.8 \times$ length in chaetiger $57-72$ (Figs 3G-J, 4F-K).

Neuropodial superior and inferior lobes. Present in anterior and middle chaetigers, both rounded, inferior one wider than superior one throughout (Figs 3G-J, 4F-K). 
Neuropodial postchaetal lobes. Rounded, half as long as neuroacicular ligule throughout.

Ventral ligules. Digitiform throughout (Figs 3G-J, 4F-K).

VENTRAL CIRRI. Digitiform throughout, becoming narrower toward posterior chaetigers (Figs 3G-J, 4F$\mathrm{K}) ; 0.7 \times$ length of ventral ligule in chaetigers $1-11,0.4 \times$ in chaetigers $21-34,0.7 \times$ in chaetigers $41-72$ (Figs 3G-J, 4F-K).
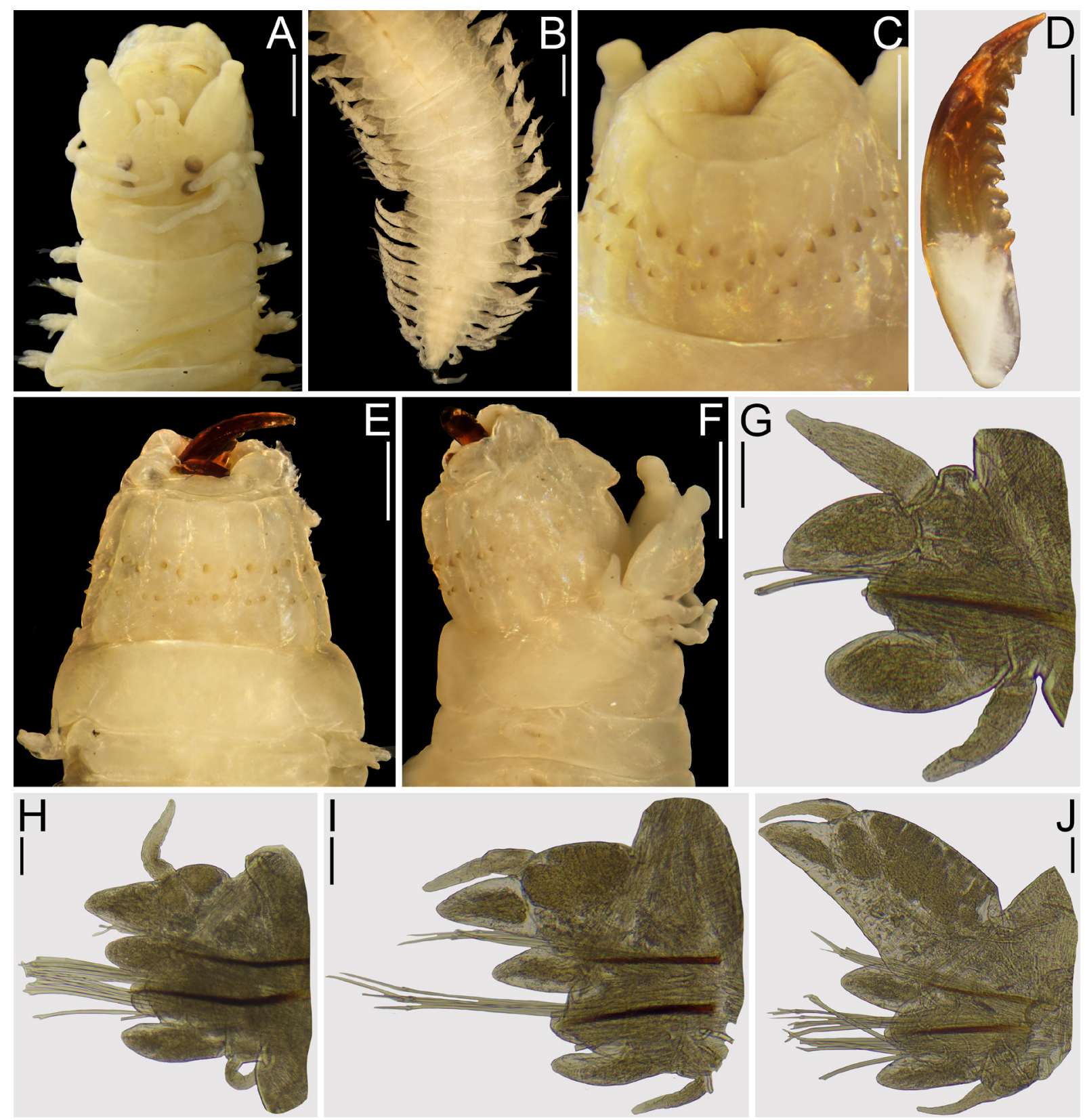

Fig. 3. Perinereis bairdii (Webster, 1884). A-C, G-J. Lectotype of Nereis bairdii (USNM 4786). D-F. Paralectotypes (USNM 1660576). A. Anterior end, dorsal view. B. Posterior end, dorsal view. C. Pharynx, ventral view. D. Left jaw, dorsal view. E. Pharynx, ventral view. F. Pharynx, lateral view. G. Chaetiger 2, right parapodium. H. Chaetiger 11, right parapodium. I. Chaetiger 34, right parapodium. J. Chaetiger 57, right parapodium. Scale bars: A-C, E-F $=0.5 \mathrm{~mm} ; \mathrm{D}, \mathrm{G}-\mathrm{J}=0.1 \mathrm{~mm}$. 
Aciculae. Amber or dark brown throughout (Figs 3G-J, 4F-K); notoaciculae absent in first two chaetigers (Figs 3G, 4F).

Notochaеtae. All homogomph symmetrical spinigers. Blades of spinigers with pectinate, minute teeth, teeth decreasing in size toward distal end.
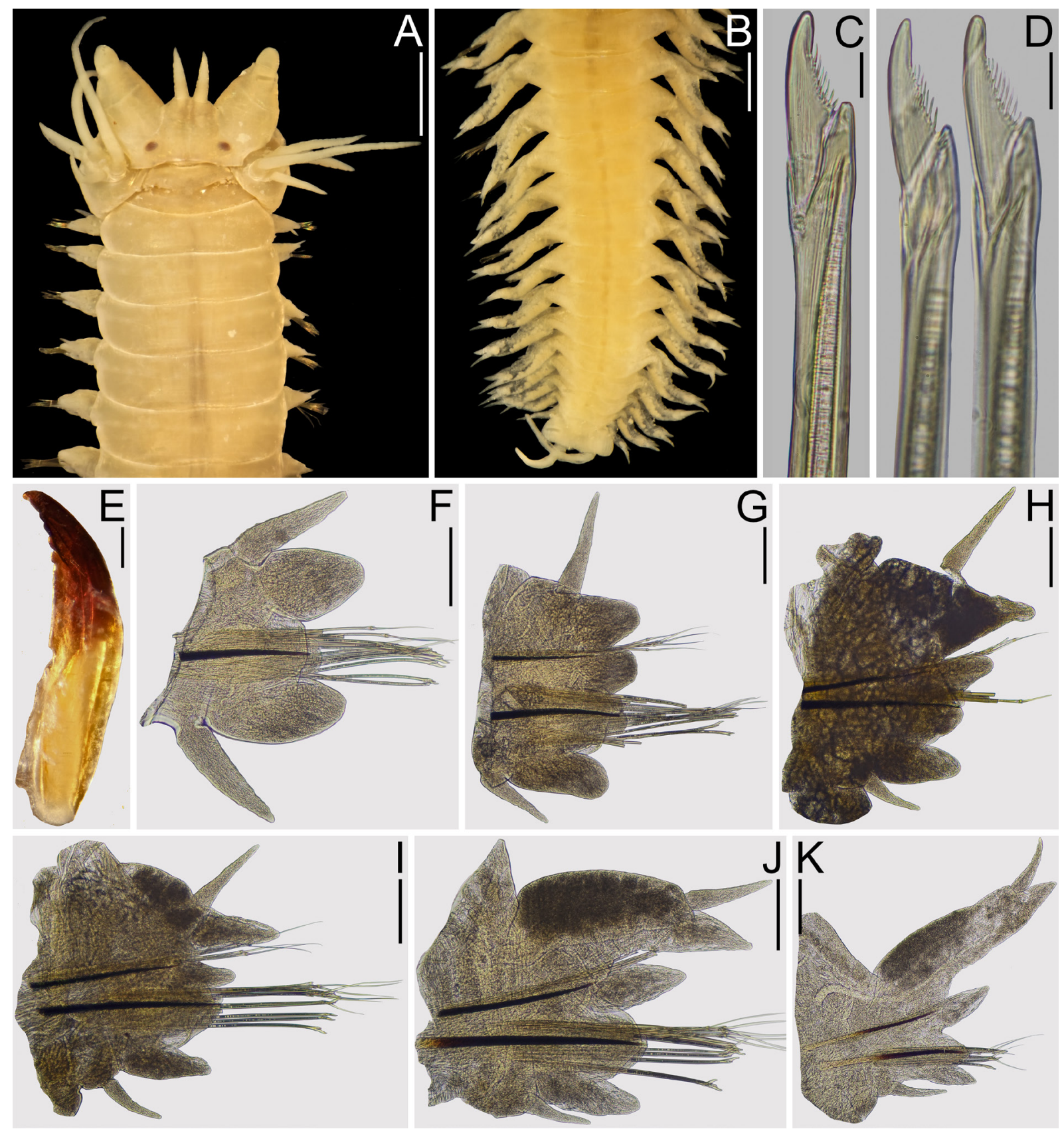

Fig. 4. Perinereis bairdii (Webster, 1884). Topotypes (USNM 1480190). A. Anterior end, dorsal view. B. Posterior end, dorsal view. C. Supra-acicular heterogomph falciger, chaetiger 59. D. Sub-acicular heterogomph falcigers, chaetiger 59. E. Right jaw, dorsal view. F. Chaetiger 1, left parapodium. G. Chaetiger 10, left parapodium. H. Chaetiger 21, left parapodium. I. Chaetiger 41, left parapodium. J. Chaetiger 59, left parapodium. K. Chaetiger 72, left parapodium. Scale bars: A-B $=0.5 \mathrm{~mm}$; $\mathrm{C}-\mathrm{D}=$ $10 \mu \mathrm{m} ; \mathrm{E}=0.25 \mathrm{~mm} ; \mathrm{F}-\mathrm{K}=0.2 \mathrm{~mm}$. 
NeURoChaEtaE. Homogomph symmetrical spinigers and heterogomph falcigers in supra-acicular fascicles, heterogomph spinigers and falcigers in sub-acicular fascicles. Neuropodial homogomph and heterogomph spinigers with blades as notopodial ones. Heterogomph falcigers pectinate, narrow teeth, two third of inner edge of blade dentate, distal tips stout (Fig. 4C-D); shafts of supra-acicular falcigers stouter than in sub-acicular ones (Fig. 4C-D).

Pygidium. Crenulated (Figs 3B, 4B); anal cirri subulate, as long as last 3-4 chaetigers (Figs 3B, 4B).

\section{Male}

Body AND MEASUREMENTS. Three specimens (USNM 1480197) complete, in excellent conditions, specimen used for description $15 \mathrm{~mm}$ long, $1.2 \mathrm{~mm}$ wide at chaetiger 10 excluding parapodia, 78 chaetigers (Fig. 5A). Pigmentation present in anterior end, brown pigment in prostomium and tentacular belt; two transverse, parallel lines of brown pigment in lateral margins of chaetigers 1-13 (Fig. 5A-C).

Prostomium. As long as wide, subpentagonal, anterior margin directed downward, dorsal groove present (Fig. 5A-C).

Antennae. Subconical with sharp tip, oriented downward, not extending beyond palps (Fig. 5A-C).

PALPS. Palpophores ovoid, swollen, $1.2 \times$ as long as wide, shorter than prostomium, subdistal transverse groove present (Fig. 5C). Palpostyles rounded.

EYES. Black, rounded, subequal, in rectangular arrangement, anterior and posterior pairs overlapped, lenses visible, posterior pair not covered by tentacular belt (Fig. 5A-C).

Tentacular Belt. As long as chaetiger 1, with straight anterior margin (Fig. 5A-C).

TENTACUlAR CIRRI. Smooth, cirrophores conspicuous, longest cirri extending backwards up to chaetiger 3 (Fig. 5A-C).

Pharynx. Dissected (Fig. 5E); jaws brown, cutting edge with 7-8 rounded teeth (Fig. 6A). Maxillary ring: $\mathrm{I}=7$ cones in triangle; $\mathrm{II}=17-16$ cones in arc; $\mathrm{III}=21$ cones in ellipse; $I V=27-23$ cones in triangle (Fig. 5E). Oral ring: $\mathrm{V}=1$ cone; $\mathrm{VI}=1-1$ smooth bar; $\mathrm{VII}-\mathrm{VIII}=37$ cones in two bands: anterior band with 10 paragnaths in furrow row with 1 cone on the regions a-e, and 11 paragnaths in ridge row with 1 cone on the regions A-F; posterior band with 16 paragnaths in a single ridge row with 2 cones on the regions $\mathrm{A}-\mathrm{D}$ and 1 cone on the regions $\mathrm{E}$ (Fig. 5E). Furrow pattern of areas VI-V-VI, $\lambda$-shaped.

Body Regions. Two regions: 1) pre-natatory region includes chaetigers 1-13, subdivided into two subregions: a) dorsal cirri in chaetigers 1-7 and ventral cirri in chaetigers 1-5 pyriform or cattail-like, and 2) chaetigers 8-13 with both dorsal and ventral cirri cirriform; 2) natatory region includes chaetigers 14 to end of body, chaetiger 14 with upper lamella in dorsal cirrus and both upper and lower lamellae in ventral cirrus, in chaetiger 15 and remaining ones also appear lower lamella in dorsal cirrus, a lamella below median ligule, ventral lamella and a basal, dorsal protrusion in neuropodial ventral ligules.

Pre-natatory region. Parapodia resembling atokous ones (Fig. 6B-E). Dorsal cirrus pyriform in chaetigers $1-3$, cattail-like in chaetiger $4-7$, and filiform in remaining chaetigers (Fig. 6B-E); $2 \times$ as long as distal lobe of dorsal ligule in chaetiger 2, 2.7 $\times$ in chaetiger 3, 2.0 $\times$ in chaetigers 7 and 10 (Fig. 6B-E); $2.6 \times$ as long as proximal lobe of dorsal ligule in chaetiger $2,2.9 \times$ in chaetiger $3,2.4 \times$ in chaetiger 7 , $1.5 \times$ in chaetiger 10 (Fig. 6B-E). Dorsal ligule digitiform in first chaetigers, becoming subconical toward posterior ones; distal lobe of dorsal ligule $1 \times$ length of median ligule in chaetiger $3,1.5 \times$ in 
chaetiger 7, $1.5 \times$ in chaetiger 10 (Fig. 6B-E). Median ligule digitiform throughout; $2.3 \times$ as long as neuroacicular ligule in chaetiger $3,1.7 \times$ in chaetiger $7,1.5 \times$ in chaetiger 10 (Fig. $6 \mathrm{~B}-\mathrm{E}$ ). Neuroacicular ligule subconical throughout; $1.7 \times$ as long as ventral ligule in chaetiger 2, $0.8 \times$ length in chaetiger 3 , $1.2 \times$ in chaetiger 7, $1.3 \times$ in chaetiger 10 (Fig. $6 \mathrm{~B}-\mathrm{E}$ ). Neuropodial superior and inferior lobes rounded, inferior one longer and wider than superior one throughout (Fig. 6B-E); neuropodial postchaetal lobe rounded, half as long as neuroacicular ligule (Fig. 6B-E). Ventral ligule digitiform throughout; $0.7 \times$ length of ventral cirrus in chaetiger $2,1 \times$ in chaetiger $3,1.3 \times$ in chaetigers 7 and 10 (Fig. 6B-E). Ventral cirrus pyriform in chaetigers $1-5$, filiform thereafter (Fig. 6B-E).

Natatory Region. Parapodia distinct from atokous ones (Fig. 6F-J). Dorsal cirrus filiform, crenulations present from chaetiger 15, decreasing in size and number toward posterior chaetigers until disappear (Fig. $6 \mathrm{~F}-\mathrm{J}$ ) $; 1.5 \times$ as long as distal lobe of dorsal ligule in chaetiger $14,2 \times$ in chaetiger $15,1.6 \times$ in chaetiger $30,1.2 \times$ in chaetiger $50,1.2 \times$ in chaetiger 72 (Fig. $6 \mathrm{~F}-\mathrm{J})$. Upper lamella of dorsal cirrus present since chaetiger 14 , flabellate throughout, larger in middle chaetigers, $0.7 \times$ length of dorsal cirrus in chaetiger 30 (Fig. 6F-J); ventral lamella after chaetiger 15, flabellate and smaller than upper lamella of dorsal cirrus throughout (Fig. 6G-J). Dorsal ligule subconical in chaetiger 14, digitiform thereafter, becoming narrower toward posterior chaetigers (Fig. $6 \mathrm{~F}-\mathrm{J}$ ); distal lobe of dorsal ligule $2.7 \times$ as long as median ligule in chaetiger $14,0.7 \times$ in chaetiger $15,1 \times$ in chaetigers $30-50,1.2 \times$ in chaetiger 72 (Fig. 6F-J). Notopodial prechaetal lobe rounded, lamelliform, present since chaetiger 15 (Fig. 6G$\mathrm{J}) ; 0.5 \times$ length of dorsal ligule in chaetiger $15,0.3 \times$ in chaetigers $30-72$ (Fig. $6 \mathrm{G}-\mathrm{J}$ ). Median ligule digitiform throughout, becoming narrower toward posterior chaetigers (Fig. $6 \mathrm{~F}-\mathrm{J}$ ); $1.4 \times$ as long as neuroacicular ligules in chaetigers $15-50,1.8 \times$ in chaetiger 72 (Fig. $6 \mathrm{~F}-\mathrm{J}$ ); small basal lamella of median ligule present since chaetiger 15, flabellate throughout (Fig. 6G-J). Neuroacicular ligule subconical in chaetiger 14, digitiform thereafter (Fig. $6 \mathrm{~F}-\mathrm{J}$ ), superior and inferior lobes absent; $1.2 \times$ as long as ventral ligule in chaetiger $14,2 \times$ in chaetiger $15,1.2 \times$ in chaetigers $30-50,0.8 \times$ in chaetiger 72 (Fig. $6 \mathrm{~F}-\mathrm{J}$ ). Neuropodial postchaetal lobe rounded in chaetiger 14, transformed into broad flabellate ventral lamella
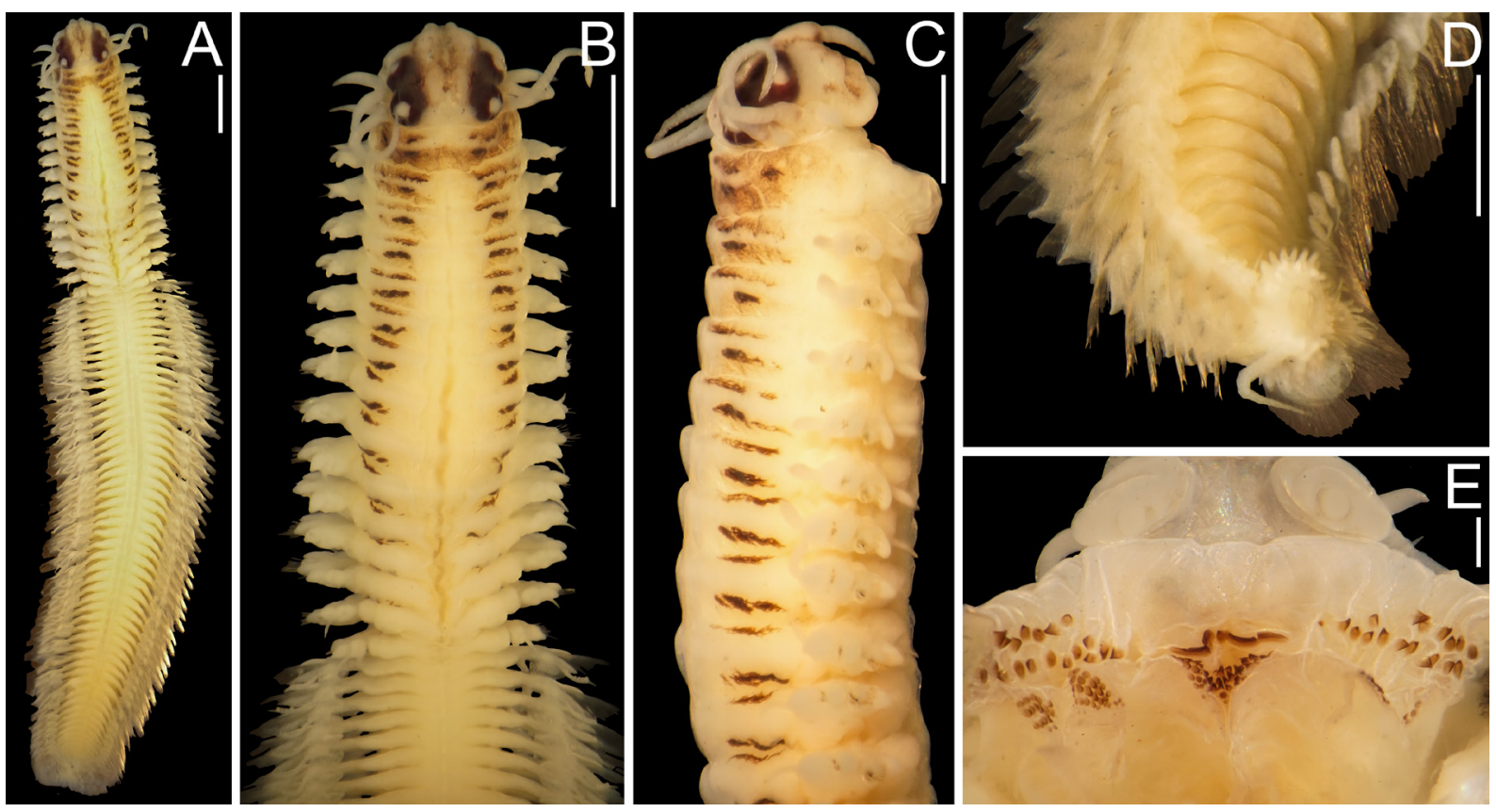

Fig. 5. Perinereis bairdii (Webster, 1884). Topotype male (USNM 1480197). A. Whole specimen, dorsal view. B. Anterior end, dorsal view. C. Same, lateral view. D. Posterior end, dorsal view. E. Pharynx dissected, ventral view. Scale bars: $A-B=1 \mathrm{~mm} ; C=0.5 \mathrm{~mm} ; \mathrm{E}=0.2 \mathrm{~mm}$. 
with a basal, dorsal protrusion thereafter (Fig. $6 \mathrm{~F}-\mathrm{J}$ ); $2 \times$ as long as neuroacicular ligule in chaetiger $15,2.5-3 \times$ in chaetigers $30-50,2 \times$ in chaetiger 75 (Fig. 6G-J). Ventral ligule subconical in chaetiger 14 , and digitiform with a small basal, dorsal lobe thereafter (Fig. $6 \mathrm{~F}-\mathrm{J}) ; 0.7 \times$ length of ventral cirrus in chaetigers $14-15,1 \times$ in chaetigers $30-50,1.2 \times$ in chaetiger 72 (Fig. 6F-J). Ventral cirrus filiform throughout (Fig. 6F-J); upper lamella divided in two subequal, digitiform lobes (Fig. 6F-J); lower lamella flabellate, $2-3 \times$ as wide as upper ones throughout (Fig. $6 \mathrm{~F}-\mathrm{J})$.

ACiCULAE. Basally amber and distally dark brown, amber region enlarges toward posterior chaetigers (Fig. 6B-J). Notoaciculae absent in first two chaetigers (Fig. 6B), proximal end rectangular in nonnatatory region and becoming flabellate in natatory one.

Noto- AND NEUROCHAETAE. Resembling atokous ones in non-natatory region, replaced with paddle-like, heterogomph chaetae with short bosses in natatory region (Fig. 6B-J).

Pygidium. Crenulated, with a rosette of papillae formed by two or three rows of papillae (Fig. 5D); anal cirrus as long as last $4-5$ chaetigers (Fig. 5D).

\section{Remarks}

Webster (1884) did not indicate where the type series was deposited. USNM records state that a group of specimens called 'Annelids collected in Bermuda in 1876-7' was received from the Wesleyan University as a gift, entered in the Worm catalog in February 1890 with the accession number 22885, and assigned catalog number USNM 4786 for the 9 syntypes of 'Nereis bairdii n. sp.' (K. Ahlfeld, USNM, pers. com.). The original description of Webster (1884) is detailed, including the illustrations of the pharynx and parapodia from several regions of the body. Remarkably, Webster described two recently revised pharyngeal features: the description of the shape of areas VI as "which have straight inner margins" (Webster 1884), i.e., the pattern of areas V$\mathrm{VI}-\mathrm{V}$, and the description of the disposition of the paragnaths in areas VII-VIII into discrete regions, i.e., furrow and ridge regions of areas VII-VIII (Conde-Vela 2018; Villalobos-Guerrero 2019).

As outlined above, two different morphological patterns were observed in the syntypes of $N$. bairdii. For the discussion in the following paragraphs, specimens with short tentacular cirri, several paragnaths in areas VII-VIII, and large dorsal ligules in posterior chaetigers are referred to as 'sp. 1'; and specimens with long tentacular cirri, a smaller number of paragnaths in areas VII-VIII, and short dorsal ligules in posterior chaetigers are referred to as 'sp. 2'.

There are some indications that Webster described Nereis bairdii using several specimens because features from the two morphological patterns are mixed in the description. Webster (1884: fig. 22) detailed an anterior end with long posterodorsal tentacular cirri, which was also included in the description: "Tentacular cirri... the posterior superior longest, reaching back to the eighth segment...", which matches with sp. 2. Webster (1884) described the arrangement of paragnaths but the number of paragnaths in most areas was not detailed, but they can be traced from his figures $22 \mathrm{a}$ and 23 . The area I was depicted with 7 paragnaths, which matches with sp. 1, although the number of paragnaths in areas II-IV lies between the range of variation of sp.1 and sp. 2. Webster (1884) described the presence of 0-3 paragnaths in area $\mathrm{V}$, but all syntypes examined have $0-1$ paragnaths in such area. Webster (1884) described areas VII-VIII as follows: "vii and viii in two series, the anterior composed of a few denticles, the posterior more numerous and smaller", which could refer to both sp. 1 and sp. 2, but the figure (Webster 1884: fig. 23) clearly shows an anterior band with a furrow row, which is absent in sp. 2. Therefore, the pharynx depicted and described (Webster 1884) belongs to a specimen from sp. 1.

Webster (1884) described the parapodia of his new species in a paragraph and depicted them in figures 24 , 25 , and 26. At the end of this paragraph, Webster mentioned that "other specimens, certainly belonging 
to this species, have the feet more delicate, the dorsal and ventral cirri a trifle longer. (figs 24a, 26a.)". Webster described the dorsal ligules as follows: "The superior lingula is enlarged (fig. 25), the dorsal cirrus moves nearer the apex of its lingula, and on the extreme posterior feet becomes a little more delicate (fig. 26)"; figure 26 shows a posterior parapodium with dorsal ligule several times longer than median ligule and ventral ligule slightly longer than neuroacicular ligule. Conversely, posterior parapodium depicted from 'other specimens' (Webster 1884: fig. 26a) shows dorsal ligule faintly longer than median ligule and ventral ligule shorter than neuroacicular ligule. Therefore, the former parapodial description is from sp. 1, whereas the illustrations of the 'other specimens' match with sp. 2 . The chaetae described are a notopodial homogomph spiniger and a neuropodial heterogomph falciger, but both drawings are
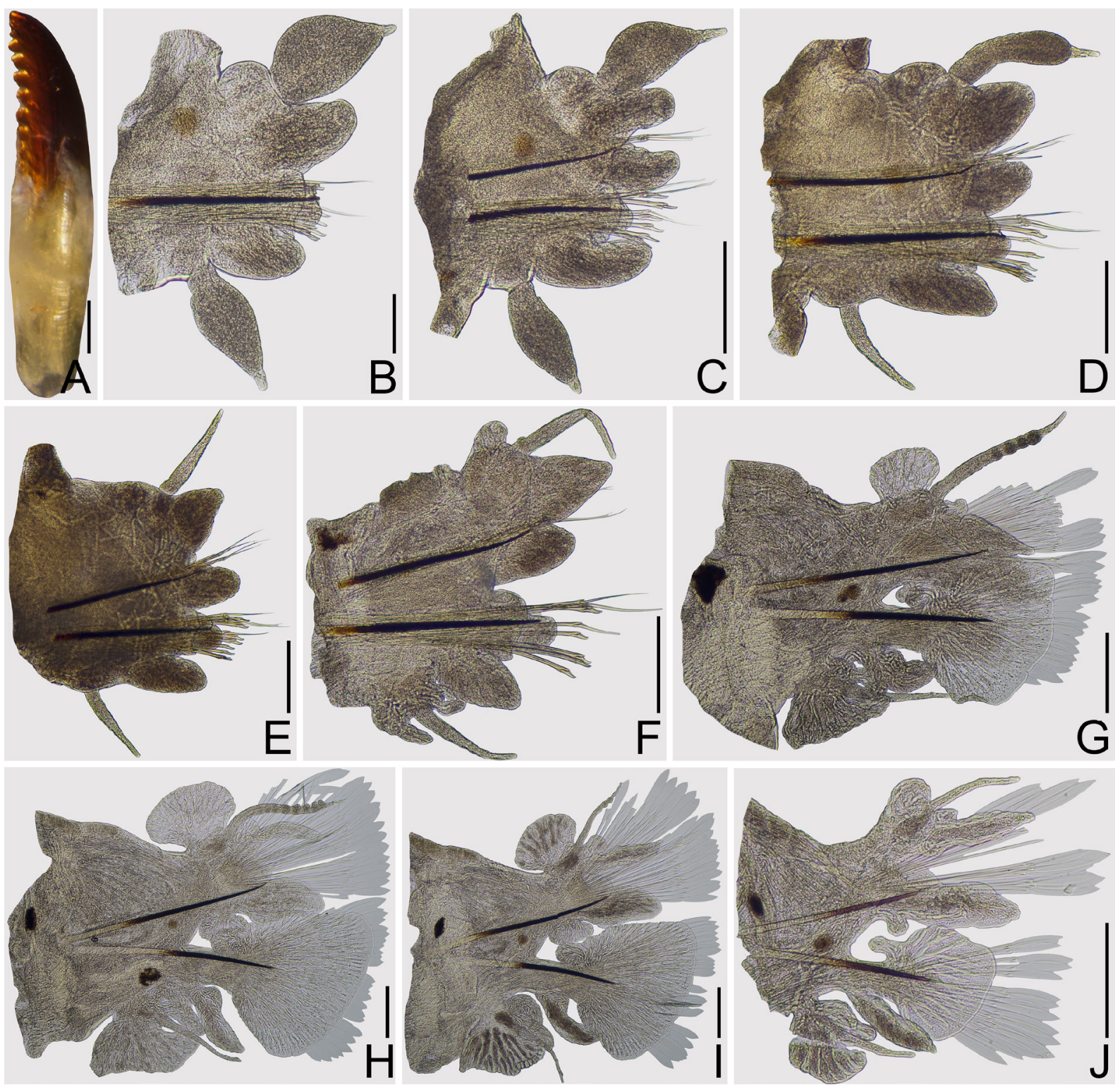

Fig. 6. Perinereis bairdii (Webster, 1884). Topotype male (USNM 1480197). A. Right jaw, dorsal view. B. Chaetiger 2, left parapodium. C. Chaetiger 3, left parapodium. D. Chaetiger 7, left parapodium. E. Chaetiger 10, left parapodium. F. Chaetiger 14, left parapodium. G. Chaetiger 15, left parapodium. H. Chaetiger 30, left parapodium. I. Chaetiger 50, left parapodium. J. Chaetiger 72, left parapodium. Scale bars: A-B, $\mathrm{J}=0.1 \mathrm{~mm} ; \mathrm{C}-\mathrm{I}=0.2 \mathrm{~mm}$. 
very schematic and match either sp. 1 or sp. 2. Finally, Webster (1884) described anal cirri as long as last ten chaetigers, matching with sp. 2.

All these pieces of information point to the fact that Webster used more than one specimen from the syntypes when describing Nereis bairdii: descriptions of pharynx and parapodia refer to sp. 1, whereas the descriptions of the anterior end, additional illustrations of the parapodia, and the anal cirri, refer to sp. 2. Despite the mix of features in the original description, the idea that Nereis bairdii has short tentacular cirri and enlarged dorsal ligules in posterior chaetigers, i.e., corresponding with sp. 1, prevailed among the contemporary authors, explaining the synonymy of Nereis bairdii with P. anderssoni because they have a very similar morphology. For example, Augener (1927) reported Nereis (Perinereis) bairdii for Curaçao, and proposed the synonymy of Nereis (Perinereis) melanocephala McIntosh, 1885 with this species, a species from Bermuda with tentacular cirri reaching to chaetiger 3 and dorsal ligules enlarged in posterior chaetigers; posteriorly, Augener (1936) reported the species for Bonaire. Monro (1933b) transferred N. bairdii to Perinereis and retained the synonymy proposed by Augener (1927). Later, Hartman (1944) examined the type material of P. anderssoni and concluded that Nereis bairdii and $N$. melanocephala are junior synonyms and maintained this viewpoint in subsequent works (Hartman 1948, 1951). Hartman (1951) reported P. anderssoni for the Gulf of Mexico (and including N. bairdii as a junior synonym) and highlighted that the species "is readily identified for having posterior notopodial lobes much prolonged...", which is reinforced when describing $P$. floridana some paragraphs below as "...posterior parapodial lobes are short, resembling those of median segments and are thus not be confused with those of $P$. anderssoni (see above).". Other records of $P$. anderssoni retained the synonymy of N. melanocephala but not mentioned N. bairdii (e.g., Díaz-Díaz \& Liñero-Arana 2002).

With all these pieces of information, it is concluded that the name Nereis bairdii is represented with specimens of sp. 1 and that specimens of sp. 2 are not N. bairdii, so the split of the syntypes is required. To redefine Nereis bairdii and to preserve the stability of the name and its application through time (ICZN 1999, Recomm. 74A), specimens of sp. 1 were selected lectotype and paralectotypes; the terms lectotype and paralectotypes have been stated in the material examined and in the description of P. bairdii, they have been described and illustrated and their data updated for its recognition (ICZN 1999, Art. 74.7, Recomm. 74A-G). Specimens of sp. 2 are shown to be an undescribed species and are identified as the new species, Perinereis websteri sp. nov.

The synonymy of Nereis (Perinereis) melanocephala with P. bairdii is retained here. Nereis (Perinereis) melanocephala was described from Bermuda from a single specimen (McIntosh 1885), and based on the original description, it agrees with P. bairdii in most features, the following being the most relevant ones: 1) anterior end with brown pigment, 2) tentacular cirri reaching chaetiger 3,3 ) tentacular belt twice longer than chaetiger 1,4) arrangement of paragnaths are almost identical and especially the size of smooth bars in areas VI, 5) dorsal ligules $2-3 \times$ longer than median ligules, 6) dorsal cirri not extending beyond the tip of the distal lobe of dorsal ligules in posterior chaetigers, 7) ventral ligules longer than neuroacicular ligules in posterior chaetigers.

Conversely, there are several differences between Perinereis bairdii and P. anderssoni: 1) in P. anderssoni, the pattern of areas V-VI-V is $\Pi$-shaped, whereas in P. bairdii it is $\lambda$-shaped; 2) in P. anderssoni, the area $\mathrm{V}$ has 3 paragnaths in a triangle and are not horizontally aligned with smooth bars in areas VI but they are posteriorly displaced, whereas $P$. bairdii has $0-1$ cones that are horizontally aligned with smooth bars; 3) in P. anderssoni, the smooth bars in areas VI are half as long as wide in area VI, whereas in $P$. bairdii they are almost as long as; 4 ) in $P$. anderssoni, the posterior band has one furrow and one ridge row, whereas in $P$. bairdii has a single ridge row only; 5) in $P$. anderssoni, there are 13 ridge regions (A-G) in areas VII-VIII, whereas in P. bairdii there are 11 ridge regions (A-F); 6) in P. anderssoni, the dorsal and ventral ligules in first two chaetigers are subconical, whereas in P. bairdii they are globose; 
7) in P. anderssoni the dorsal cirri are longer than dorsal ligules in anterior chaetigers and becoming shorter toward posterior ones, whereas in P. bairdii they are shorter than dorsal ligules throughout body; 8 ) in $P$. anderssoni, the neuropodial heterogomph falcigers are stouter and the length of inner margin edentate is longer than in $P$. bairdii.

It seems reasonable to assume that most reports of Perinereis anderssoni from the Caribbean Sea represent $P$. bairdii, but it is unclear. For example, $P$. anderssoni from Venezuelan coasts (Liñero-Arana \& ReyesVásquez 1979; Díaz-Díaz \& Liñero-Arana 2002; Vanegas-Espinosa et al. 2007) differs from P. bairdii in the following features: 1) in Venezuelan specimens, there are 46-85 paragnaths in area III, whereas in P. bairdii they are 6-22 paragnaths; 2) in Venezuelan specimens, dorsal cirri in posterior chaetigers are $0.6 \times$ as long as proximal lobes and are $1.5 \times$ as long as distal lobes of dorsal ligules, whereas in P. bairdii, dorsal cirri are $0.3 \times$ as long as proximal lobes and are $1.7 \times$ as long as distal lobes of dorsal ligules; 3) in Venezuelan specimens, the dorsal ligules are at least $3.5 \times$ as long as the median ligules and the ventral ligules are $2-4 \times$ longer than the neuroacicular ligules in posterior chaetigers, whereas in P. bairdii, the dorsal ligules are $3.3 \times$ as long as the median ligules and the ventral ligules are $1.2 \times$ than the neuroacicular ligules. A record of $P$. anderssoni from the Mexican Caribbean (Salazar-Vallejo \& Jiménez-Cueto 1997) differs from P. bairdii in the following features: 1) in Caribbean specimens, the dorsal cirri are $1.4 \times$ as long as the distal lobes of the dorsal ligules and the median ligules are as long as the neuroacicular ligules in anterior chaetigers, whereas in P. bairdii the dorsal cirri are $1.2 \times$ longer and the median ligules are $2.4 \times$ longer; 2 ) in Caribbean specimens, the dorsal cirri are $0.5 \times$ as long as proximal lobes and as long as distal lobes of dorsal ligules in posterior chaetigers, whereas in P. bairdii the dorsal cirri are $0.3 \times$ as long as the proximal lobes and are $1.7 \times$ as long as the distal lobes. Further studies will clarify whether records of $P$. anderssoni from the Gulf of Mexico and the Mexican Caribbean, and other regions of the Caribbean Sea, are different species.

\section{Distribution}

Bermuda.

Perinereis websteri sp. nov. urn:1sid:zoobank.org:act:1F30E930-AAA6-4F85-810A-76EEB08070C9

Figs 7-9, 13

\section{Etymology}

Named after Harrison Edwin Webster, as a tribute to his work on polychaete taxonomy and studying the nereidid species reviewed here.

\section{Type material}

Holotype

BERMUDA • 1 spec.; Bermuda, Jews Bay, Public Wharf, near Waterlot Inn; 26 Nov. 1976; M.L. Jones leg.; intertidal sand; USNM 1490807.

\section{Paratypes}

BERMUDA • 6 specs; same data as for holotype; USNM $1490808 \bullet 2$ specs; Bermuda, S side of Ferry Reach, 1/2 mile along Kindley Field Road; 23 Nov. 1976; intertidal, rock/mud; USNM 1490809.

\section{Additional material}

BERMUDA • 1 spec.; Bermuda, Bay E of BBS; 25 Sep. 1982; 0.75 m depth; M.L. Jones, GJ leg.; associated with red mangrove roots; 32 ppt; USNM 1490804 - 2 specs; Bermuda, $1 / 2$ mile along Kindley Field Road, S side of Ferry Reach; 23 Nov. 1976; intertidal, rock/mud; USNM 1490805 - 8 specs; 
Bermuda, between Ferry Reach and St Georges Harbor, S of Stokes Pt; 21 Sep. 1982; 1 m depth; M.L. Jones, G.J. leg.; from gravel; 32 ppt; USNM 1490806 • 4 specs; Bermuda; 1876; G.B. Goode leg.; USNM 1660577 (syntypes of Nereis bairdii removed from USNM 4786).

\section{Type locality}

Jews Bay, Bermuda.

\section{Description}

Body AND MEASUREMENTS. Holotype (USNM 1490807) complete, $35 \mathrm{~mm}$ long, $1.4 \mathrm{~mm}$ wide at chaetiger 10, 87 chaetigers (Fig. 8A). Two paratypes (USNM 1490809) in good conditions; one paratype complete, $75 \mathrm{~mm}$ long, $2.5 \mathrm{~mm}$ wide at chaetiger 10, 104 chaetigers; another paratype incomplete, $67 \mathrm{~mm}$ long, $2.5 \mathrm{~mm}$ wide at chaetiger 10, 83 chaetigers. Non-type material from syntypes of Nereis bairdii (USNM 1660577), one specimen dissected, $35 \mathrm{~mm}$ long, $1.6 \mathrm{~mm}$ wide at chaetiger 10,90 chaetigers. Pigmentation not observed in all specimens (Figs 7-8).

Prostomium. Subpentagonal, as long as wide, anterior region distally entire, as long as posterior region, dorsal groove present (Figs 7A-B, 8F); anterolateral gap between antenna and palpophore as long as diameter of antennae (Figs 7A-B, 8F).

ANTENNAE. Cirriform, not passing palps, half as long as prostomium, gap between them as long as basal wide of antennae (Figs 7A-B, 8F).

PALps. Palpophores subconical, swollen, $1.2 \times$ as long as wide, as long as prostomium, subdistal transverse groove present (Figs 7A-B, 8F). Palpostyles digitiform (Fig. 7A-B).

EYES. Rounded, anterior and posterior pairs subequal, in trapezoidal arrangement, posterior pair not covered by anterior margin of tentacular belt (Figs 7A-B, 8F).

TENTACULAR Belt. $1.5 \times$ as long as chaetiger 1 , covering posterior pair of eyes, anterior dorsal margin omega-shaped (Figs 7A-B, 8F).

Tentacular Cirri. Smooth, longest cirri reaching end of chaetiger 7 (Figs 7A-B, 8F).

Pharynx. Dissected in holotype, everted in paratypes and non-type specimens (Figs 7C-D, 8B-C, H) and in non-types (Fig. 8D-E); jaws brown, 10 teeth with truncate tips (Fig. 9I). Maxillary ring: I $=3$ cones (3-11); II $=10-9$ cones (8-19) in arc; III $=9$ cones (8-13), 7 in a central ellipse and one cone at each lateral side of the ellipse; IV $=18-19$ cones $(18-27)$ in arc (Figs 7C-D, 8B-E). Oral ring: $\mathrm{V}=1$ cone (11) displaced toward posterior margin of ring; $\mathrm{VI}=1-1$ smooth bar (1-1), rarely 4-6 paragnaths behind each bar; VII-VIII $=16$ cones (10-16) in two bands: anterior band with one furrow row with 6 cones with 1 cone on the regions a-c; second band with one furrow row with 4 cones with 1 in each regions $\mathrm{a}-\mathrm{b}$, and one ridge row with 6 cones, 2 cones in region $\mathrm{A}$ and 1 cone in each regions $\mathrm{B}-\mathrm{C}$ (Figs $7 \mathrm{C}-\mathrm{D}$, 8B-E, H, 13). Furrow pattern of areas VI-V-VI, $\lambda$-shaped (Figs 7D, 8B, D, 13).

DORSAL CIRRI. Digitiform in first chaetigers, subconical with blunt tip thereafter; attached basally to dorsal ligule in anteriormost chaetigers, medially in middle chaetigers, and subdistally in posterior chaetigers (Figs 7E-H, 9A-H); $1.2 \times$ as long as distal lobe of dorsal ligule in chaetiger $2,1.4 \times$ in chaetigers $10-50$, $1.8 \times$ in chaetigers $70-75,2.5 \times$ in chaetigers $82-100($ Figs $7 \mathrm{E}-\mathrm{H}, 9 \mathrm{~A}-\mathrm{H}) ; 3.7 \times$ as long as proximal lobe of dorsal ligule in chaetiger $2,5 \times$ in chaetigers $10-31,1.5 \times$ in chaetigers $50-75,1.2 \times$ in chaetigers 82-100 (Figs 7E-H, 9A-H). 
Dorsal LIGULES. Subconical with blunt tip in anterior and middle chaetigers, becoming pennant-like toward posterior chaetigers, with distal lobes longer than proximal ones in first chaetigers, becoming as long as in anterior chaetigers, and shorter than in middle and posterior chaetigers (Figs 7E-H, 9A$\mathrm{H})$. Distal lobe of dorsal ligule subconical with blunt tip throughout; $2 \times$ as long as median ligule in chaetigers $10-31,1.2 \times$ in chaetiger $50,2 \times$ in chaetigers $70-75,1 \times$ in chaetiger $82,2 \times$ in chaetiger 100 (Figs 7E-H, 9A-H).
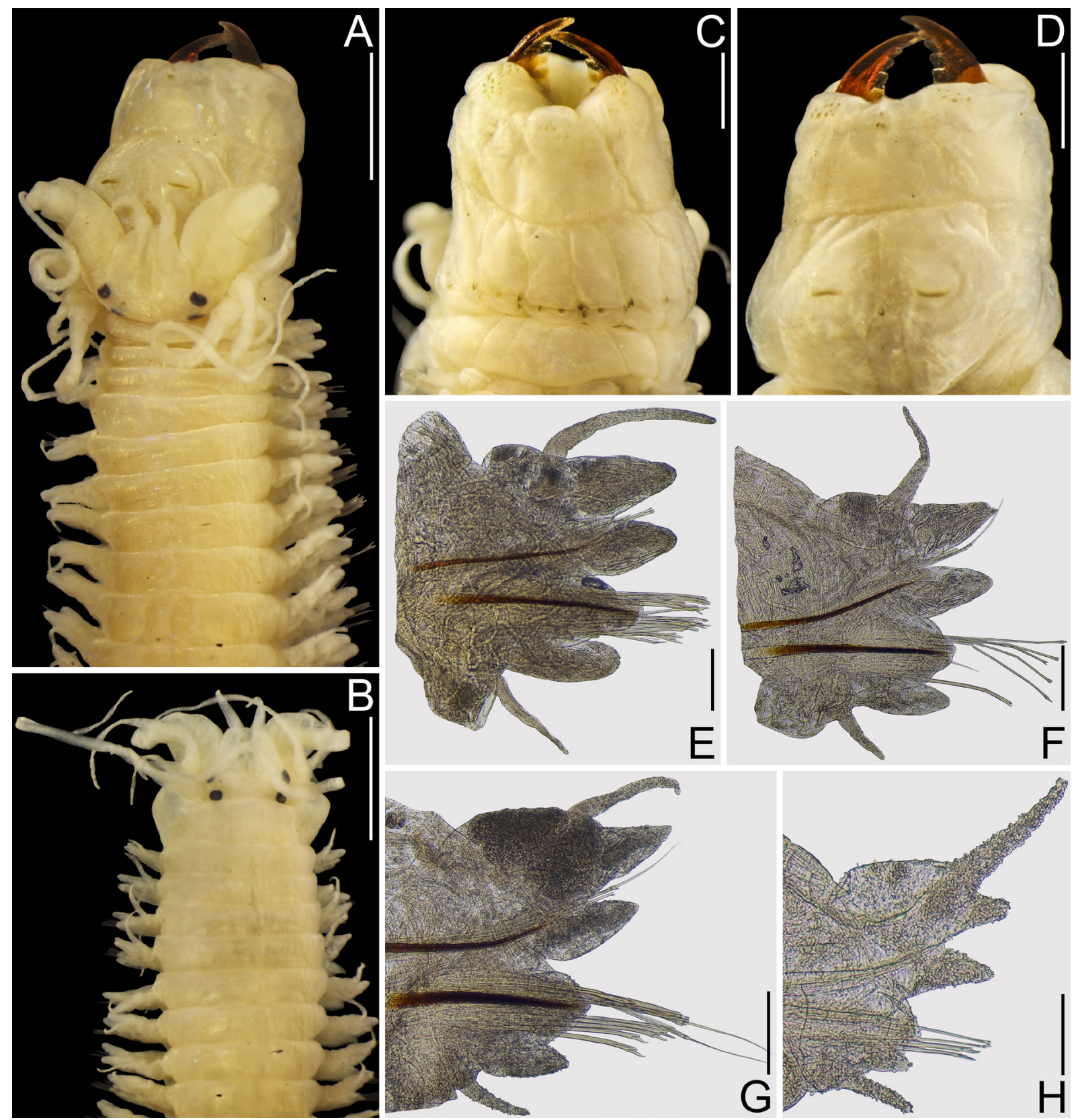

Fig. 7. Perinereis websteri sp. nov. Non-types (USNM 1660577, from syntype series of Nereis bairdii Webster, 1884). A. Anterior end, dorsal view. B. Anterior end, dorsal view. C. Pharynx, dorsal view. D. Same, ventral view. E. Chaetiger 10, left parapodium. F. Chaetiger 43, left parapodium. G. Chaetiger 69, left parapodium. H. Chaetiger 84 , left parapodium. Scale bars: A-B $=1 \mathrm{~mm}$; C-D $=$ $0.5 \mathrm{~mm} ; \mathrm{E}-\mathrm{G}=0.2 \mathrm{~mm} ; \mathrm{H}=0.1 \mathrm{~mm}$. 
Median ligules. Digitiform in anterior chaetigers, becoming subconical with blunt tip thereafter (Figs $7 \mathrm{E}-\mathrm{H}, 9 \mathrm{~A}-\mathrm{H}$ ); $2.5 \times$ as long as neuroacicular ligule in chaetiger $10,1.8 \times$ in chaetiger $31,2 \times$ in chaetigers $50-82,1.3 \times$ in chaetiger 100 (Figs 7E-H, 9A-H).
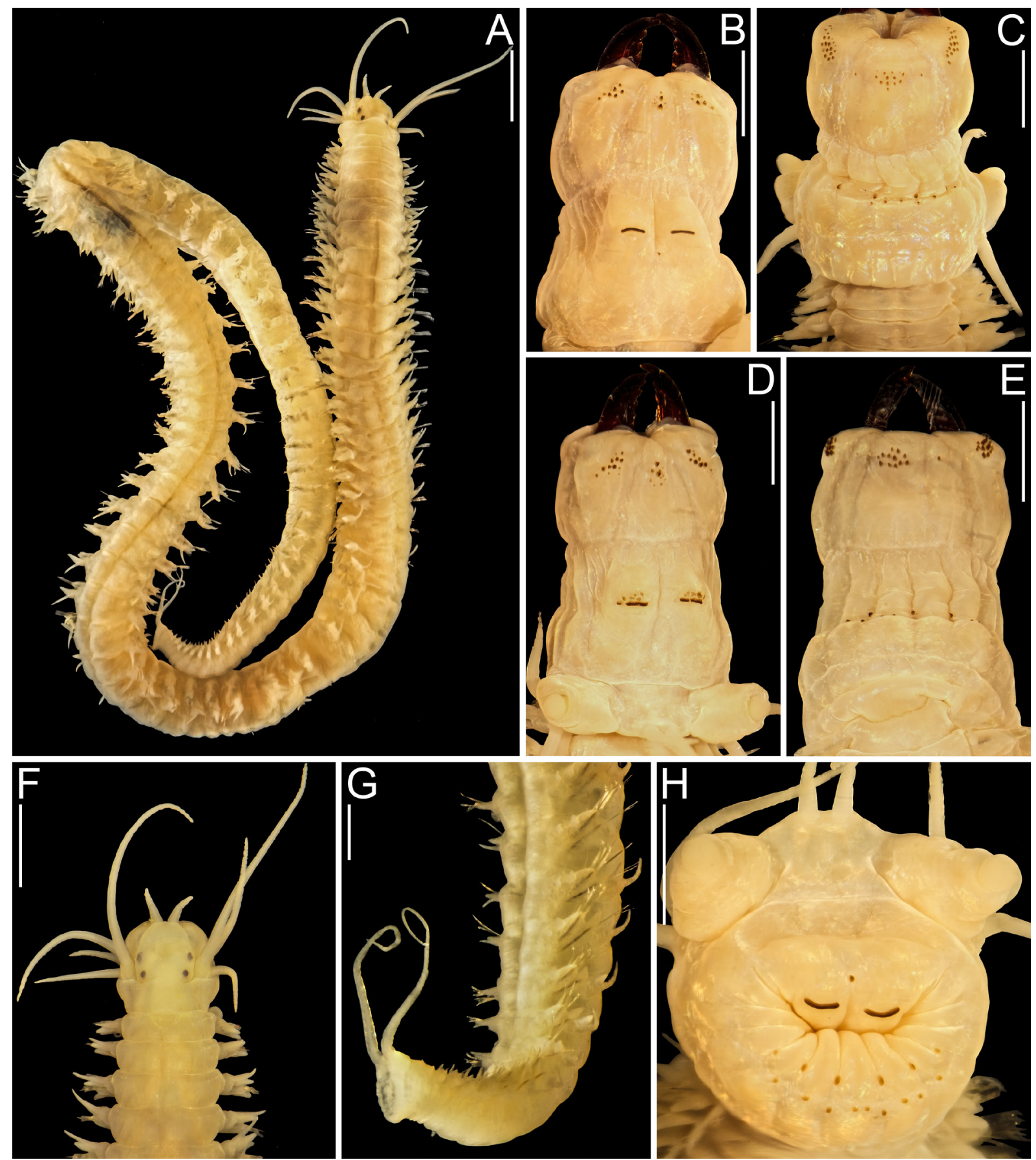

Fig. 8. Perinereis websteri sp. nov. A, F-G. Holotype (USNM 1490807). B-C, H. Paratype (USNM 1490809). D-E. Non-type (USNM 14900805). A. Whole specimen, dorsal view. B. Pharynx, dorsal view. C. Same, ventral view. D. Pharynx, dorsal view. E. Same, ventral view. F. Anterior end, dorsal view. G. Posterior end, dorsal view. H. Pharynx, ventral view. Scale bars: A $=1.5 \mathrm{~mm}$; $\mathrm{B}-\mathrm{H}=1 \mathrm{~mm}$. 
Neuroacicular ligules. Subconical throughout (Figs 7E-H, 9A-H); $0.5 \times$ length of ventral ligule in chaetiger 2, $1 \times$ in chaetigers $10-70,1.5 \times$ in chaetiger 75-82, $2 \times$ in chaetiger $100($ Figs $7 \mathrm{E}-\mathrm{H}, 9 \mathrm{~A}-\mathrm{H}$ ).

NeUROPODIAL SUPERIOR AND INFERIOR LOBES. Present in anterior chaetigers, both rounded, inferior one wider than superior one throughout (Figs 7E-H, 9A-H).

Neuropodial postchaetal Lobes. Rounded, half as long as neuroacicular ligule throughout.

Ventral Ligules. Digitiform throughout (Figs 7E-H, 9A-H). Ventral cirrus subconical with blunt tips throughout (Figs 7E-H, 9A-H); $1 \times$ length of ventral ligule in chaetiger 2, $0.8 \times$ in chaetiger $10,0.6 \times$ in chaetigers $31-50,1 \times$ in chaetigers $70-75,1.2 \times$ in chaetiger $82,1.5 \times$ in chaetiger $100($ Figs $7 \mathrm{E}-\mathrm{H}$, 9A-H).

NotochaEtAE. All homogomph symmetrical spinigers. Blades of spinigers with pectinate, minute teeth, teeth decreasing in size toward distal end.

NeURochaEtaE. Homogomph symmetrical spinigers and heterogomph falcigers in supra-acicular fascicles, heterogomph spinigers and falcigers in sub-acicular fascicles. Neuropodial homogomph and heterogomph spinigers with blades as notopodial ones. Heterogomph falcigers pectinate, narrow teeth, three quarter of inner edge of blade dentate, distal tips stout (Fig. $9 \mathrm{~J}-\mathrm{N}$ ); shafts of supra-acicular falcigers stouter than in sub-acicular ones (Fig. 9J-N).

Pygidium. Crenulated, funnel-shaped (Fig. 8G); anal cirri subulate, as long as last 10 chaetigers (Fig. 8G).

\section{Remarks}

Perinereis websteri sp. nov. is a sympatric species that co-occurs with P. bairdii in Bermuda. As discussed above, the type series of Nereis bairdii had two morphological patterns, and one of them belongs to $P$. websteri sp. nov.; the differences between them were discussed in the remarks of $P$. bairdii.

Perinereis websteri sp. nov. resembles $P$. floridana (Ehlers, 1868) by having long tentacular cirri, dorsal ligules with similar development along body, and the shape of neuropodial heterogomph falcigers, but there are relevant differences among their atokes: 1) in P. websteri sp. nov., the anterior and posterior regions of the prostomium are subequal, whereas in $P$. floridana the anterior region is $1.7 \times$ as long as the posterior one; 2) in P. websteri sp. nov., the anterior margin of tentacular belt is omega-shaped, whereas in P. floridana it is straight; 3 ) in P. websteri sp. nov., areas VI sometimes can have conical paragnaths, whereas in P. floridana there are smooth bars only; 4) in $P$. websteri sp. nov., there are no paragnaths in ridge regions $\mathrm{D}$ and furrow regions $\mathrm{c}-\mathrm{d}$ of the posterior band in the areas VII-VIII, whereas in P. floridana they are present in regions D and sometimes present in regions $\mathrm{c}-\mathrm{d}$; 5) In P. websteri sp. nov., the dorsal cirri are $1.4 \times$ as long as distal lobes of dorsal ligules in middle chaetigers and $2.5 \times$ in posterior chaetigers, whereas in P. floridana they are $0.8-0.9 \times$ longer in middle and posterior chaetigers; 6 ) in $P$. websteri sp. nov., the dorsal cirri are $1.2 \times$ as long as proximal lobes in posterior chaetigers, whereas in P. floridana they are $0.8-0.9 \mathrm{x} ; 7)$ in $P$. websteri sp. nov., the dorsal ligules are $2 \times$ as long as median ligules in posterior chaetigers, whereas in P. floridana they are $2.4 \times$ longer; 8 ) in $P$. websteri sp. nov., the neuroacicular ligules are $1.5-2.0 \times$ as long as ventral ligules in posterior chaetigers; whereas in P. floridana they are $0.8 \times$ as long; 9) in $P$. websteri sp. nov., the ventral cirri are $1.0-1.2 \times$ as long as ventral ligules in posterior chaetigers, whereas in $P$. floridana they are $0.7 \times$ as long.

\section{Distribution}

Bermuda. 


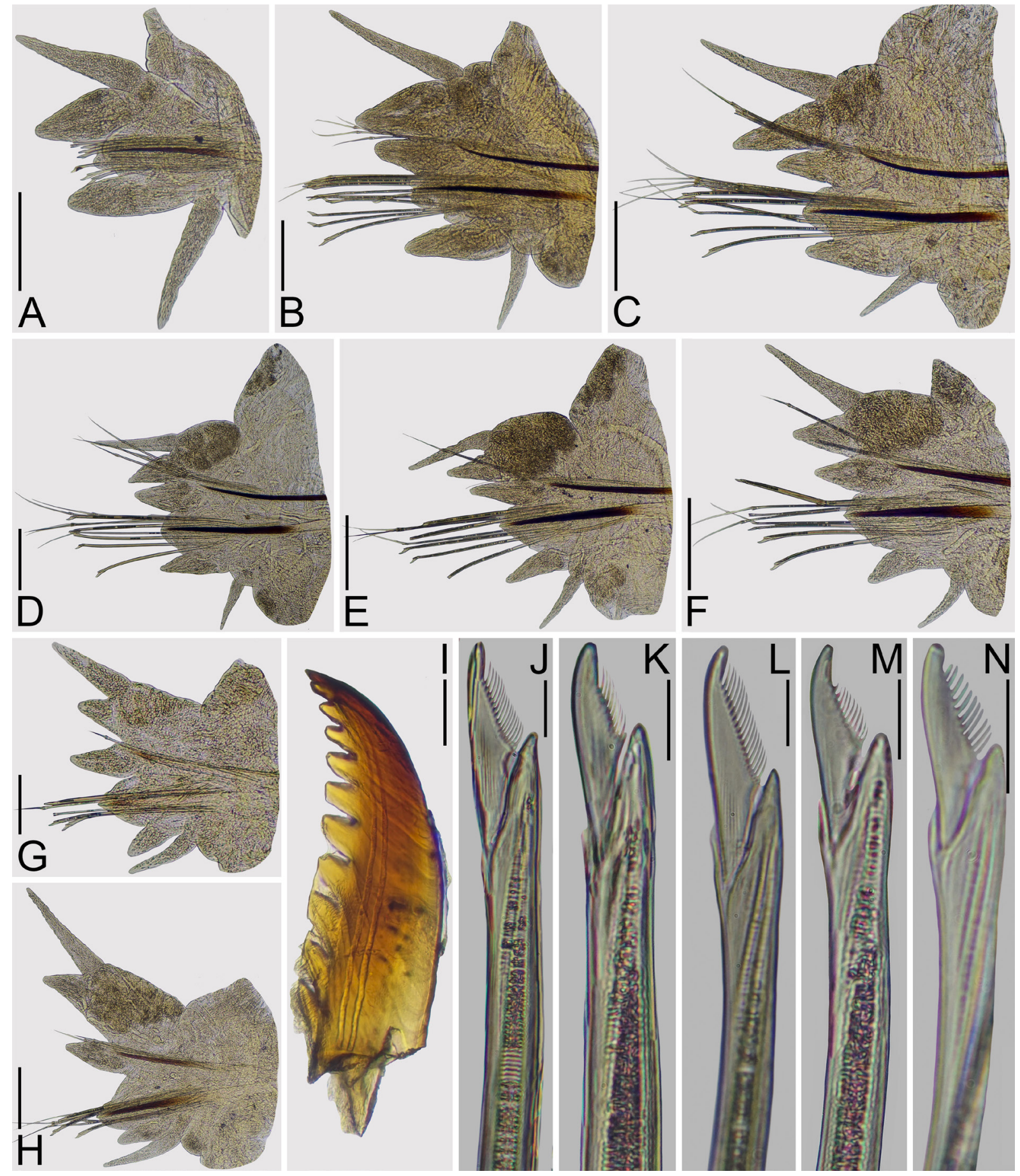

Fig. 9. Perinereis websteri sp. nov. A-G, I-N. Holotype (USNM 1490807). H. Paratype (USNM 1490809). A. Chaetiger 2, right parapodium. B. Chaetiger 10, right parapodium. C. Chaetiger 31, right parapodium. D. Chaetiger 50, right parapodium. E. Chaetiger 70, right parapodium. F. Chaetiger 75, right parapodium. G. Chaetiger 82, right parapodium. H. Chaetiger 100, right parapodium. I. Right jaw, dorsal view. J. Supra-acicular heterogomph falciger, chaetiger 31. K. Supra-acicular heterogomph falciger, chaetiger 75. L. Sub-acicular heterogomph falciger, chaetiger 31. M. Sub-acicular heterogomph falciger, chaetiger 75. N. Sub-acicular heterogomph falciger, chaetiger 82 . Scale bars: A-F, H $=0.2 \mathrm{~mm}$; $\mathrm{G}, \mathrm{I}=0.1 \mathrm{~mm} ; \mathrm{J}-\mathrm{N}=10 \mu \mathrm{m}$. 
Perinereis floridana (Ehlers, 1868)

Figs 1, 10-11, 13

Nereis floridana Ehlers, 1868: 503-506.

Perinereis floridana - Langerhans 1880: 19 (new combination only). — Monro 1933c: 256. — SalazarVallejo \& Jiménez-Cueto 1997: 367, figs 8, 32-33 (partim). — De León-González \& Solís-Weiss 1998: 683-684, figs 6-7.

\section{Type material examined}

\section{Syntypes}

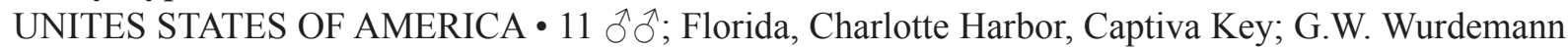
leg.; MCZ ANNa-119.

\section{Additional material examined}

UNITED STATES OF AMERICA - 1 spec.; Florida, Charlotte County, Lemon Bay; 26 54'50" N, 82²0'26" W; 11 Jan. 1938; O. Hartman leg.; LACM-AHF 7377 • 3 specs; same collection data as for preceding; 14 Jan. 1938; O. Hartman leg.; LACM-AHF 7376.

MEXICO • 16 specs; Yucatan, Isla Cerritos; 18 Jan. 1991; Sergio I. Salazar-Vallejo leg.; ECOSUR P1100

- 1 spec.; Quintana Roo, Isla Contoy; 11 Oct. 1993; Sergio I. Salazar-Vallejo leg.; ECOSUR P1112.

\section{Description}

\section{Epitoke}

Body AND MEASUREMENTS. Syntypes (MCZ ANNa-119) heteronereis males complete, in good conditions, one selected for description, $32 \mathrm{~mm}$ long, $3 \mathrm{~mm}$ wide at chaetiger 10 excluding parapodia, 110 chaetigers (Fig. 10A). Pigmentation not observed in all specimens (Fig. 10A).

Prostomium. Subpentagonal, $1.5 \times$ as wide as long, anterior region distally entire, shorter than posterior region, dorsal groove present (Fig. 10B); anterolateral gap between antenna and palpophore $1.5 \times$ as long as diameter of antennae (Fig. 10B).

AntenNAE. Cirriform, not passing palps, half as long as prostomium, gap between them as long as basal wide of antennae (Fig. 10B).

PaLPs. Palpophores subconical, swollen, $1.6 \times$ as wide as long, shorter than prostomium, subdistal transverse groove present (Fig. 10B). Palpostyles rounded.

EYES. Rounded, anterior and posterior pairs subequal, in rectangular arrangement, anterior and posterior pair overlapped, posterior pair not covered by anterior margin of tentacular belt (Fig. 10B).

Tentacular Belt. As long as chaetiger 1, anterior dorsal margin omega-shaped (Fig. 10B).

TENTACULAR CIRRI. Smooth, cirrophores conspicuous, longest cirri extending backwards up to end of chaetiger 7 (Fig. 10B).

Pharynx. Everted (Fig. 10B); jaws brown, 7-8 teeth, proximal ones ensheathed (Fig. 10C-D). Maxillary ring: $\mathrm{I}=2$ cones in a vertical row; $\mathrm{II}=6-7$ cones in arc; $\mathrm{III}=9$ cones, 7 in a central ellipse and one cone at each lateral side of the ellipse; IV $=13-14$ cones in arc (Fig. 10C-D). Oral ring: $\mathrm{V}=1$ cone displaced toward posterior margin of ring; $\mathrm{VI}=1-1$ smooth bar; VII-VIII $=24$ cones in two bands: anterior band with one furrow row with 6 cones with 1 cone on the regions a-c, and 1 cone in ridge region $\mathrm{A}$; second 
band with one furrow row with 8 cones with 1 cone on the regions a-d, and one ridge row with 9 cones, 3 cones in region A and 1 cone in each regions B-D (Figs 10C-D, 13); rarely anterior and posterior bands very close to each other (Fig. 10D). Furrow pattern of areas VI-V-VI, $\lambda$-shaped (Figs 10C, 13).

Body REgions. Two regions: 1) pre-natatory region includes chaetigers 1-17, subdivided into two subregions: a) dorsal cirri in chaetigers $1-7$ and ventral cirri in chaetigers $1-5$ pyriform or cattail-like, and 2) chaetigers 8-17 with both dorsal and ventral cirri cirriform; 2) natatory region includes chaetigers 18 to end of body, chaetiger 18 with upper lamella in dorsal cirrus and both upper and lower lamellae in ventral cirrus, in chaetiger 19 and remaining ones also appear lower lamella in dorsal cirrus, a lamella below median ligule, ventral lamella and a basal, dorsal protrusion in neuropodial ventral ligules.

Pre-natatory Region. Parapodia resembling atokous ones (Fig. 10I-L). Dorsal cirrus cattail-like in chaetigers 1-7, filiform thereafter (Fig. 10I-L); $1.5 \times$ as long as distal lobe of dorsal ligule in chaetigers 2-17 (Fig. 10I-L); 3.2 $\times$ as long as proximal lobe of dorsal ligule in chaetiger 2, 2.3 $\times$ in chaetiger 6 , $2 \times$ in chaetigers 10-17. Dorsal ligule digitiform in first chaetiger, becoming subconical with blunt tip toward posterior ones; distal lobe of dorsal ligule $1.3 \times$ as long as median ligule in chaetigers $6-10$, $1.6 \times$ in chaetiger 17 (Fig. 10I-L). Median ligule subconical with blunt tip throughout; $3 \times$ as long as neuroacicular ligule in chaetiger $6,3.5 \times$ in chaetigers $10-17$ (Fig. 10I-L). Neuroacicular ligule subconical with blunt tip throughout. Neuropodial superior and inferior lobes rounded, inferior one longer and wider than superior one throughout (Fig. 10I-L); neuropodial postchaetal lobe rounded, half as long as neuroacicular ligule. Ventral ligule digitiform throughout; $1.4 \times$ as long as neuroacicular ligule in chaetiger $2,1.8 \times$ in chaetigers $6-10,1.4 \times$ in chaetiger 17 (Fig. 10I-L). Ventral cirrus cattail-like in chaetigers $1-5$, filiform thereafter; $0.7 \times$ length of ventral ligule throughout (Fig. 10I-L).

NATATORY REGION. Parapodia distinct from atokous ones (Fig. 10M-O). Dorsal cirrus filiform, crenulations present from chaetiger 18, decreasing in size and number toward posterior chaetigers until disappear (Fig. 10M-O); $1.7 \times$ as long as distal lobe of dorsal ligule in chaetiger $18,1.4 \times$ in chaetiger $40,1 \times$ in chaetiger 95 (Fig. 10M-O). Upper lamella of dorsal cirrus present since chaetiger 18, flabellate throughout, larger in middle chaetigers, as long as dorsal cirrus in chaetiger 40 (Fig. 10M-O); lower lamella since chaetiger 19, flabellate and much smaller than upper lamella of dorsal cirrus throughout (Fig. 10M-O). Dorsal ligule subconical with blunt tip in chaetiger 18, digitiform thereafter, becoming narrower toward posterior chaetigers (Fig. 10M-O); distal lobe of dorsal ligule $1.4 \times$ as long as median ligule in chaetigers $18-40,1.2 \times$ in chaetiger 95 (Fig. 10M-O). Median ligule subconical with blunt tip in chaetiger 18, digitiform thereafter, becoming broader toward middle chaetigers (Fig. 10M-O); $4 \times$ as long as neuroacicular ligule in chaetiger $18,2.6 \times$ in chaetiger $40,1.6 \times$ in chaetiger 95 (Fig. 10M-O); small basal lamella of median ligule present since chaetiger 19, flabellate throughout (Fig. 10M-O). Neuroacicular ligule subconical with blunt tip in chaetiger 18, digitiform thereafter, superior and inferior lobes absent (Fig. 10M-O). Neuropodial postchaetal lobe rounded in chaetiger 18, transformed into broad flabellate ventral lamella (Fig. 10M-O); $2 \times$ as long as neuroacicular ligule in chaetiger $40,1.5 \times$ in chaetiger 95 (Fig. 10M-O). Ventral ligule subconical with blunt tip in chaetiger 18, digitiform with a small basal, dorsal lobe thereafter (Fig. 10M-O); $2 \times$ as long as neuroacicular ligule in chaetiger $18,1.2 \times$ in chaetiger 40,1 $\times$ in chaetiger 95 . Ventral cirrus filiform throughout; as long as ventral ligule throughout (Fig. 10M-O). Upper lamella of ventral cirrus divided in two subequal, digitiform lobes (Fig. 10M-O); lower lamella of ventral cirrus flabellate, $2-3 \times$ as wide as upper ones throughout (Fig. 10M-O).

ACICULAE. Basally amber and distally dark brown, amber region enlarges toward posterior chaetigers (Fig. 10I-O). Notoaciculae absent in first two chaetigers (Fig. 10I), proximal end rectangular in nonnatatory region and becoming flabellate in natatory one (Fig. 10I-O). 
Noto- AND NeURochaetaE. Resembling atokous ones in non-natatory region (Fig. 10E-H), replaced with paddle-like, heterogomph chaetae with short bosses in natatory region (Fig. 10N-O).

Pygidium. Crenulated, with a rosette of papillae formed by two or three rows of papillae; anal cirrus as long as last 12-14 chaetigers (Fig. 10A).

\section{Atoke}

Body AND MEASUREMENTS. Specimens from Isla Cerritos (ECOSUR P1100) in excellent condition, best preserved specimen complete, $52 \mathrm{~mm}$ long, $2.8 \mathrm{~mm}$ wide at chaetiger 10 excluding parapodia, 107 chaetigers. Pigmentation faded out; pale lines present, fingerprint-like pattern present from chaetiger 8 .

Prostomium. Subtriangular, $1.2 \times$ as long as wide, anterior region distally entire, $1.7 \times$ as long as posterior region, dorsal groove present (Fig. 11A); anterolateral gap between antenna and palpophore shorter than diameter of antennae (Fig. 11A).

AnTENNAE. Subconical, not passing palps, half as long as prostomium, gap between them shorter than basal wide of antennae (Fig. 11A).

PALPS. Palpophores subconical, swollen, $1.2 \times$ as long as wide, as long as prostomium, subdistal transverse groove present. Palpostyles rounded or digitiform.

EYES. Rounded, anterior and posterior pairs subequal, in trapezoidal arrangement, wide shorter than basal wide of antennae, sometimes posterior pair partly covered by anterior margin of tentacular belt (Fig. 11A).

TENTACULAR BELT. $1.4 \times$ as long as chaetiger 1 , sometimes slightly covering posterior pair of eyes, anterior dorsal margin straight (Fig. 11A).

TENTACUlaR CIRRI. Moniliform, not jointed, longest cirri reaching end of chaetigers 7-8 (Fig. 11A).

Pharynx. Dissected; jaws brown, cutting edge with 7-8 teeth, proximal ones ensheathed (Fig. 11H). Maxillary ring: $\mathrm{I}=2$ cones in vertical line; $\mathrm{II}=7-9(7-10)$ cones in arc; III $=13(10-14)$ cones in rectangle; IV = 16-17 (14-19) cones in arc. Oral ring: $\mathrm{V}=1$ cone; $\mathrm{VI}=1-1$ smooth bars; VII-VIII = 18 cones in two bands: anterior band with 4 paragnaths in a single furrow row with 1 cone on the regions $\mathrm{a}-\mathrm{b}$ (sometimes 1 cone on regions $\mathrm{c}$ and $\mathrm{A}-\mathrm{B}$ ); posterior band with 6 cones in furrow row with 1 cone on the regions a-c (sometimes 1 cone on regions $\mathrm{d}$ ), and 8 paragnaths in ridge row with 2 cones on region $\mathrm{A}$ and 1 cone on the regions B-D (sometimes 1 additional cone on region A) (Fig. 14). Furrow pattern of areas VI-V-VI, $\lambda$-shaped.

DorSAL CIRRI. Digitiform in first chaetigers, filiform thereafter, attached basally to dorsal ligule in anteriormost chaetigers, medially thereafter (Fig. 11C-G); $1.3 \times$ as long as distal lobe of dorsal ligule in chaetigers 2 and 10, $0.8-0.9 \times$ length thereafter; $3.7 \times$ as long as proximal lobe of dorsal ligule in chaetiger $2,2.3 \times$ in chaetiger $10,0.8-0.9 \times$ length thereafter $($ Fig. $11 \mathrm{C}-\mathrm{G})$.

Dorsal Ligules. Subconical with blunt tip in anterior and middle chaetigers, becoming pennant-like toward posterior chaetigers, with distal lobes longer than proximal ones in first chaetigers, becoming as long as in middle chaetigers and shorter than in posterior chaetigers (Fig. 11C-G). Distal lobe of dorsal ligule subconical throughout; $1.3 \times$ as long as median ligule in chaetiger 10, $1.8 \times$ in chaetigers 28 and $61,2.4 \times$ in chaetiger 91 (Fig. $11 \mathrm{C}-\mathrm{G}$ ). 
Median Ligules. Digitiform in anterior chaetigers, becoming subconical with blunt tips in middle chaetigers and digitiform to lanceolate in posterior ones (Fig. $11 \mathrm{C}-\mathrm{G}) ; 1.2 \times$ as long as neuroacicular ligule in chaetiger $10,1.8 \times$ in chaetigers 28 and $61,1.5 \times$ in chaetiger 91 (Fig. 11C-G).

Neuroacicular ligules. Subconical with blunt tip throughout (Fig. 11C-G). Neuropodial superior and inferior lobes present in anterior chaetigers, both rounded, inferior one wider than superior one throughout (Fig. 11C-G).

Neuropodial Postchaetal LOBEs. Rounded, half as long as neuroacicular ligule throughout.

Ventral ligules. Digitiform throughout (Fig. 11C-G); $1.4 \times$ as long as neuroacicular ligule in chaetiger 2, $1 \times$ in chaetigers 10 and $28,1.2 \times$ in chaetigers 61 and 91 (Fig. $11 \mathrm{C}-\mathrm{G})$.

VENTRAL CIRRI. Subconical throughout (Fig. $11 \mathrm{C}-$ G); $0.8 \times$ as long as ventral ligule in chaetiger 2, $0.5-$ $0.6 \times$ in chaetigers $10-61,0.7 \times$ in chaetiger $91($ Fig. $11 \mathrm{C}-\mathrm{G})$.

NotochaETAE. All homogomph symmetrical spinigers. Blades of spinigers with basal pectinate, coarse teeth, becoming minute toward distal end.

NeUROCHAETAE. Homogomph symmetrical spinigers and heterogomph falcigers in supra-acicular fascicles, heterogomph spinigers and falcigers in sub-acicular fascicles. Neuropodial homogomph spiniger as notopodial ones (Fig. 11L). Heterogomph spinigers with blades pectinate, minute teeth and decreasing in size toward distal end (Fig. 11K). Heterogomph falcigers pectinate, long and narrow teeth, $7 / 10$ of inner edge of blade dentate, distal tips stout, stouter in supra-acicular falcigers (Fig. 11I-J).

Pygidium. Crenulated, bilobate (Fig. 11B); anal cirri subulate, as long as last 5 chaetigers (Fig. 11B).

\section{Remarks}

Records of Perinereis floridana in the Gran Caribbean region are scarce (Salazar-Vallejo 1996; Dean 2012). This species was described based on epitoke specimens, but most of its records are based on atokes. It is relevant because Perinereis species lack a caudal region with non-transformed parapodia, so parapodial features attributed to the atokes of $P$. floridana in posterior chaetigers do not come from the original description. Ehlers (1868) placed P. floridana in a group characterized by dorsal ligules of similar size along the body and not expanded or widened (in posterior chaetigers), parapodia with a similar development along the body, paragnaths in all pharyngeal areas, and with both conical and transverse (bars) paragnaths. The parapodial features can differ in atoke and epitoke specimens in Perinereis species as shown in this work, so possibly Ehlers justified the inclusion of $P$. floridana in this group using the paragnath arrangement and its comparison with another close species, $P$. cultrifera, which match with the mentioned features.

Perhaps the atoke morphology of $P$. floridana was also taken from Fauvel (1923) when he synonymized Nereis floridana and other 8 species with Perinereis cultrifera because of the presence of a single smooth bar on each area VI, although Fauvel recognized they differ in the number of paragnaths in the area V. Fauvel (1923) described parapodia of $P$. cultrifera as follows: dorsal and median ligules subequal, with dorsal cirri slightly surpassing tips of dorsal ligules, and both neuroacicular and ventral ligules shorter than median ligules, with short ventral cirri, in posterior parapodia the ligules become sharper and the notopodial ligules are longer than neuropodial ones. For example, Wesenberg-Lund (1949) recorded 'P. cultrifera Gr. var. floridana Ehl.' from Faror, Iran citing Fauvel and his paragnath-based grouping.

Fauvel's synonymy was not followed in all cases. Horst (1924) recorded Nereis (Perinereis) floridana from Balabalagan islands and declared he followed Gravier instead. Hartman (1938a) examined the type 

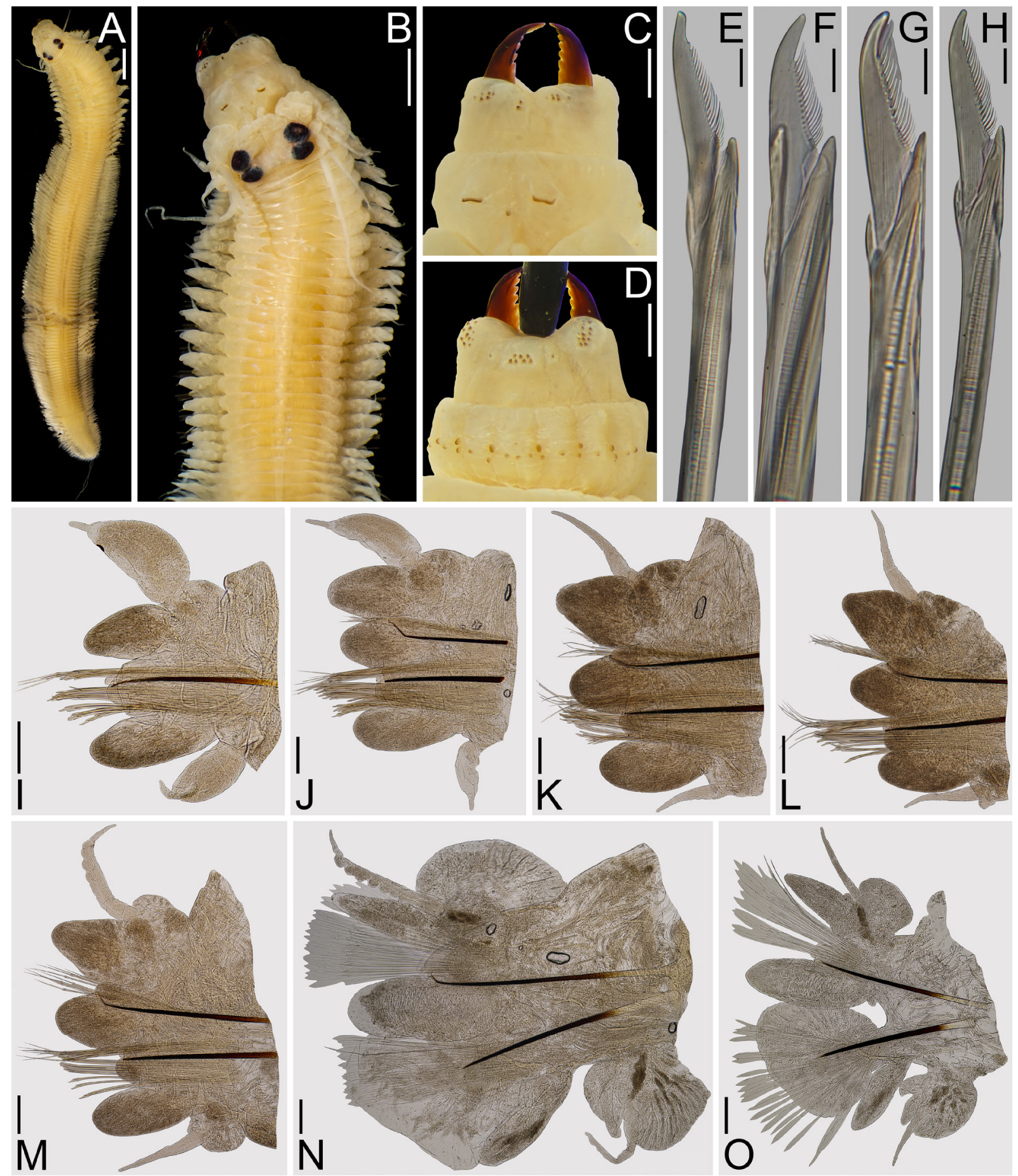

Fig. 10. Perinereis floridana (Ehlers, 1868). Syntypes of Nereis floridana (MCZ ANNa-119). A. Whole specimen, dorsal view. B. Anterior end, dorsal view. C. Pharynx, dorsal view. D. Pharynx, ventral view. E. Supra-acicular heterogomph falciger, chaetiger 6. F. Supra-acicular heterogomph falciger, chaetiger 17. G. Sub-acicular heterogomph falciger, chaetiger 6. H. Sub-acicular heterogomph falciger, chaetiger 17. I. Chaetiger 2, right parapodium. J. Chaetiger 6, right parapodium. K. Chaetiger 10, right parapodium. L. Chaetiger 17, right parapodium. M. Chaetiger 18, right parapodium. N. Chaetiger 40, right parapodium. O. Chaetiger 95, right parapodium. Scale bars: $A=2 \mathrm{~mm} ; \mathrm{B}=1 \mathrm{~mm} ; \mathrm{C}-\mathrm{D}=0.5 \mathrm{~mm}$; $\mathrm{E}-\mathrm{H}=10 \mu \mathrm{m} ; \mathrm{I}-\mathrm{O}=0.2 \mathrm{~mm}$. 
material of $P$. floridana but omitted further comments because there was a redescription by Langerhans (1880: pl. 15 fig. 24a-e), but actually Langerhans (1880) described some atoke specimens from Madeira as Perinereis floridana based on their supposed similarity only without further comments. Monro (1933c) disagreed with Fauvel about the synonymy with $P$. cultrifera and reported $P$. floridana for Dry Tortugas, Florida, but without description or figures. Later, Hartman (1951) reported atokes and epitokes of $P$. floridana from Lemon Bay, Florida, and cited Monro (1933c), but some specimens differ in the following features: 1) area $V$ has 3 paragnaths and 2) sometimes two bars in areas VI. Andrew \& Andrew (1953) reported P. floridana from North Bimini and highlighted the species has middle chaetigers resembling posterior ones, contrary to $P$. anderssoni. Finally, Salazar-Vallejo \& Jiménez-Cueto (1997) described atokes as P. floridana with specimens from the Yucatan Peninsula, and de León-González \&
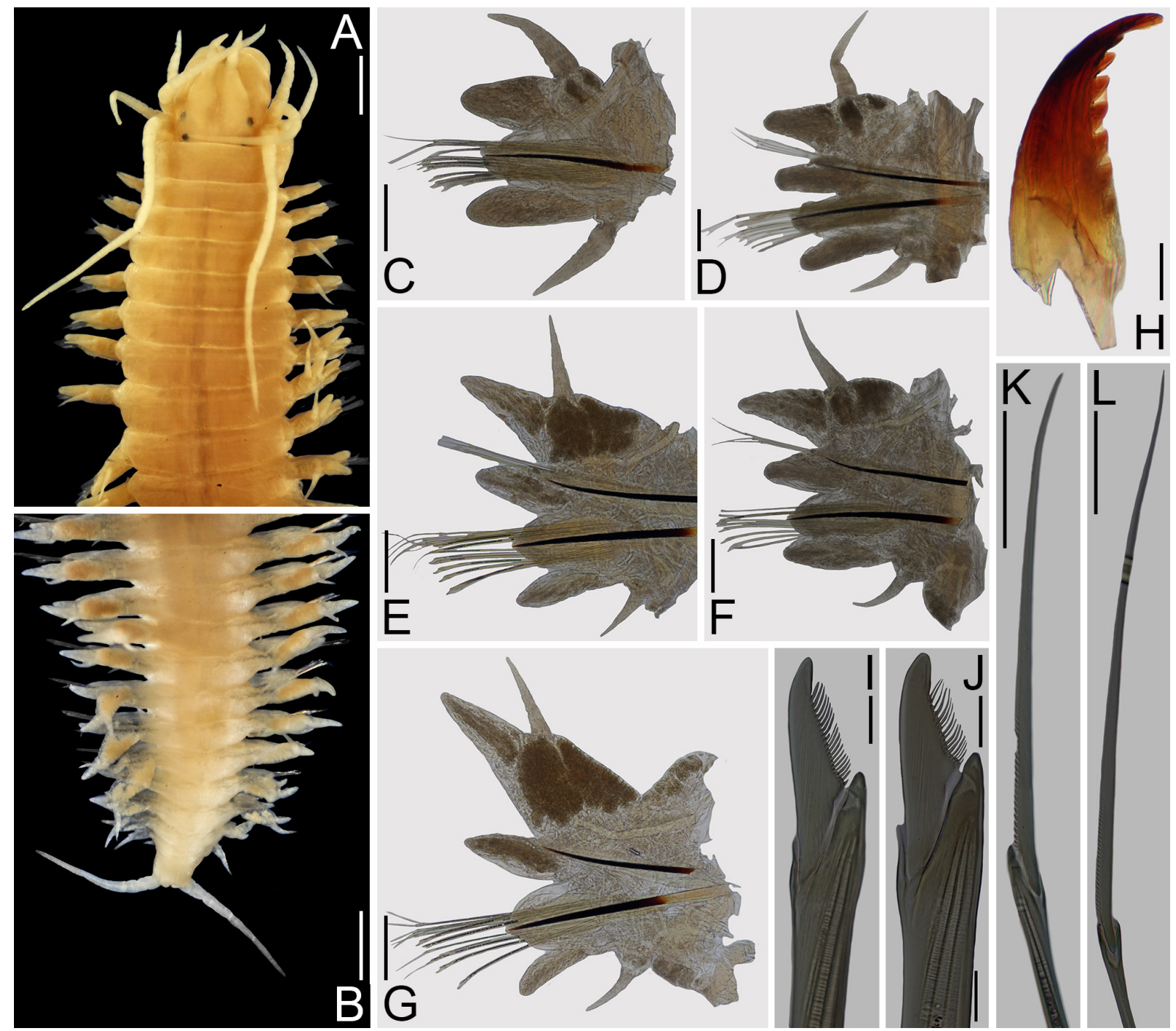

Fig. 11. Perinereis floridana (Ehlers, 1868). Non-types (ECOSUR P1100). A. Anterior end, dorsal view. B. Posterior end, dorsal view. C. Chaetiger 2, right parapodium. D. Chaetiger 10, right parapodium. E. Chaetiger 28, right parapodium. F. Chaetiger 61, right parapodium. G. Chaetiger 91, right parapodium. H. Left jaw, dorsal view. I. Supra-acicular heterogomph falciger, chaetiger 61. J. Subacicular heterogomph falciger, chaetiger 61. K. Sub-acicular heterogomph spiniger, chaetiger 61 . L. Supra-acicular homogomph spiniger, chaetiger 61. Scale bars: A-B $=1 \mathrm{~mm}$; $-\mathrm{H}=0.25 \mathrm{~mm}$; $\mathrm{I}-\mathrm{J}=$ $10 \mu \mathrm{m} ; \mathrm{K}-\mathrm{L}=50 \mu \mathrm{m}$. 
Solís-Weiss (1998) described atokes and female epitokes using specimens from Florida and the Yucatan Peninsula, and they agreed on that $P$. floridana have dorsal cirri not extending beyond the tip of distal lobes of dorsal ligules in middle and posterior chaetigers, and dorsal ligules in posterior chaetigers slightly longer than in anterior and middle chaetigers but not widened.

Here, the set of features used to determine atokes specimens belong to $P$. floridana are from the tentacular belt, the pharynx, and the chaetigers (anterior chaetigers of atokes, chaetigers 8-17 in the pre-natatory region of epitokes): 1) length of longest tentacular cirri, 2) shape and number of teeth in jaws, 3) similar number and arrangement of paragnaths in oral ring, especially areas I and III, 2) position of single paragnath in area $\mathrm{V}$ and size of smooth bars in areas VI, 3) similar number and arrangement of paragnaths in areas VII-VIII, 4) similar neuroacicular falcigers in anterior chaetigers, 5) similar ratios among notopodial processes and between ventral ligules and ventral cirri in anterior chaetigers. Main parapodial differences (excepting dorsal and ventral cirri) between atokes (anterior chaetigers) and epitokes (non-natatory region) described here are 1) both notopodial and neuropodial ligules more rounded in epitokes, and 2) relative size of neuropodial ligules. There are similar differences between atokes and epitokes of $P$. bairdii and $P$. cariboea, which are discussed below.

Based on the main morphological atokous of $P$. floridana, i.e., the long tentacular cirri, the presence of a single cone in areas $\mathrm{V}$ and a single smooth bar on each area VI, the two rows of paragnaths in areas VII-VIII, and parapodia with slight changes between middle and posterior chaetigers, closely resembles P. websteri sp. nov., but they differ as discussed in the remarks section of the latter species. Santos (2007) recorded $P$. floridana from Rocas Atoll, Brazil, but the specimens described differ from $P$. floridana as follows: 1) in Brazilian specimens, chaetiger 1 has dorsal cirri $2.4 \times$ as long as the distal lobe of the dorsal ligule, whereas in P. floridana they are $1.3 \times$ longer; 2 ) in Brazilian specimens, middle and posterior chaetigers, have dorsal cirri longer than distal lobes of dorsal ligules, whereas in $P$. floridana they are subequal or shorter; 3) in Brazilian specimens, middle chaetigers have both dorsal and median ligules subequal, and in posterior chaetigers dorsal ligules are $1.5 \times$ as long as median ones, whereas in P. floridana dorsal ligules are $1.8 \times$ as long as median ligules in middle chaetigers and $2.4 \times$ longer in posterior ones. Other records of P. floridana outside the Gulf of Mexico and the Caribbean Sea, as in the Indian Ocean (e.g., Horst 1924; Yousefi et al. 2011), are likely distinct species and need to be reassessed.

Regardless of the different prostomial features, the length of largest tentacular cirri, and the pharyngeal arrangement, males of $P$. floridana also differs from males of $P$. bairdii in the following key parapodial features: 1) in P. bairdii, the natatory region starts in chaetiger 14, whereas in P. floridana it starts in chaetiger $18 ; 2$ ) in $P$. bairdii, the first chaetiger from the natatory region (14) has dorsal ligules larger than in the corresponding chaetiger in P. floridana (18); 3) in P. bairdii, both dorsal and ventral lamellae are shorter along the natatory chaetigers than in P. floridana; 4) in P. bairdii, the median ligules along the natatory chaetigers are shorter than in P. floridana.

\section{Distribution}

Gulf of Mexico, Caribbean Sea.

Perinereis cariboea De León-González \& Solís-Weiss, 1998

Figs $12-13$

Perinereis cariboea de León-González \& Solís-Weiss, 1998: 677-680, figs 3a-e.

\section{Type material examined}

Holotype

MEXICO • 1 spec.; Quintana Roo, Bahia Ascencion, Pajaros Point; 6 Oct. 1983; V. Solís-Weiss leg.; USNM 180694. 


\section{Additional material examined}

MEXICO • 2 đðં; Quintana Roo, Isla Contoy; 2 Mar. 2001; S.I. Salazar-Vallejo and L.F. Carrera-Parra leg.; ECOSUR P3209.

\section{Description of male}

Body and measurements. Two specimens (ECOSUR P3209), one specimen complete, $20 \mathrm{~mm}$ long, $2.5 \mathrm{~mm}$ wide at chaetiger 10 excluding parapodia, 67 chaetigers (Fig. 12A), another one incomplete, $19 \mathrm{~mm}$ long, $2 \mathrm{~mm}$ wide at chaetiger 10 excluding parapodia, 62 chaetigers. Pigmentation present in anterior end, dark brown pigment in the anterior margin of prostomium and inner margins of palps, a continuous broad band with a row of white spots at the tentacular belt and dorsum of chaetigers 1-3, pigment fades at the center of the chaetigers $4-7$, and become in two lateral rows until chaetiger 13 (Fig. 12A-C).

Prostomium. $1.6 \times$ as wide as than long, subpentagonal, anterior margin directed downward, dorsal groove present (Fig. 12A-C).

AntennAe. Subconical, oriented downward, half as long as prostomium, not extending beyond palps (Fig. 12A-C).

Palps. Palpophores ovoid, swollen, as long as wide, shorter than prostomium, subdistal transverse groove present (Fig. 12C). Palpostyles globose.

EYES. Black, rounded, subequal, in rectangular arrangement, diameter $4-5 \times$ longer than basal diameter of antennae, anterior and posterior pairs overlapped, lenses not visible, posterior pair slightly covered by tentacular belt (Fig. 12A-C).

Tentacular Belt. As long as chaetiger 1, with straight anterior margin (Fig. 12A-C).

TENTACULAR CIRRI. Smooth, cirrophores conspicuous, longest cirri extending backwards up to chaetiger 4 (Fig. 12A-B).

PharynX. Everted in one specimen (Fig. 12C-D); jaws brown, cutting edge with 6-7 rounded teeth. Maxillary ring: $\mathrm{I}=9$ cones in round; $\mathrm{II}=13-14$ cones in arc; $\mathrm{III}=22$ cones in ellipse; $\mathrm{IV}=17-18$ cones in round (Fig. 12C-D). Oral ring: V = none; VI $=2-2$ smooth bar; VII-VIII $=19$ cones in two bands: anterior band with 6 paragnaths in furrow row with 1 cone on the regions a-c, and 7 paragnaths in ridge row with 1 cone on the regions A-D; posterior band with 6 paragnaths in a single ridge row with 1 cone on the regions C-E (Figs 12C-D, 13). Furrow pattern of areas VI-V-VI, $\lambda$-shaped (Figs 12C, 13).

Body REgIONS. Two regions: 1) pre-natatory region includes chaetigers 1-13, subdivided into two subregions: a) dorsal cirri in chaetigers 1-7 and ventral cirri in chaetigers 1-5 pyriform or cattail-like, and 2) chaetigers 8-13 with both dorsal and ventral cirri cirriform; 2) natatory region includes chaetigers 14 to end of body, chaetiger 14 with upper lamella in dorsal cirrus and both upper and lower lamellae in ventral cirrus, in chaetiger 15 and remaining ones also appear lower lamella in dorsal cirrus, a lamella below median ligule, ventral lamella and a basal, dorsal protrusion in neuropodial ventral ligules.

Pre-natatory Region. Parapodia resembling atokous ones (Fig. 12E-G). Dorsal cirrus pyriform in chaetigers $1-7$, and filiform in remaining chaetigers (Fig. 12E-G); $1.8 \times$ as long as distal lobe of dorsal ligule in chaetigers $2-6,1.6 \times$ in chaetiger 12 (Fig. 12E-G); $7.5 \times$ as long as proximal lobe of dorsal ligule in chaetiger $2,2 \times$ in chaetiger $6,1.7 \times$ in chaetiger 12 . Dorsal ligule rounded in first chaetigers, becoming subconical with blunt tip toward posterior ones; distal lobe of dorsal ligule $1.2 \times$ as long as median ligules in chaetigers 6-12 (Fig. 12E-G). Median ligule digitiform throughout, $2 \times$ as long as 
neuroacicular ligule in chaetigers 6-12 (Fig. 12E-G). Neuroacicular ligule subconical throughout; $1.7 \times$ as long as ventral ligule in chaetiger $2,1 \times$ in chaetigers $6-12$ (Fig. 12E-G). Neuropodial superior and inferior lobes very small, almost inconspicuous; neuropodial postchaetal lobe rounded, half as long as neuroacicular ligule. Ventral ligule digitiform throughout; $1.2 \times$ as long as ventral cirrus in chaetiger 2,
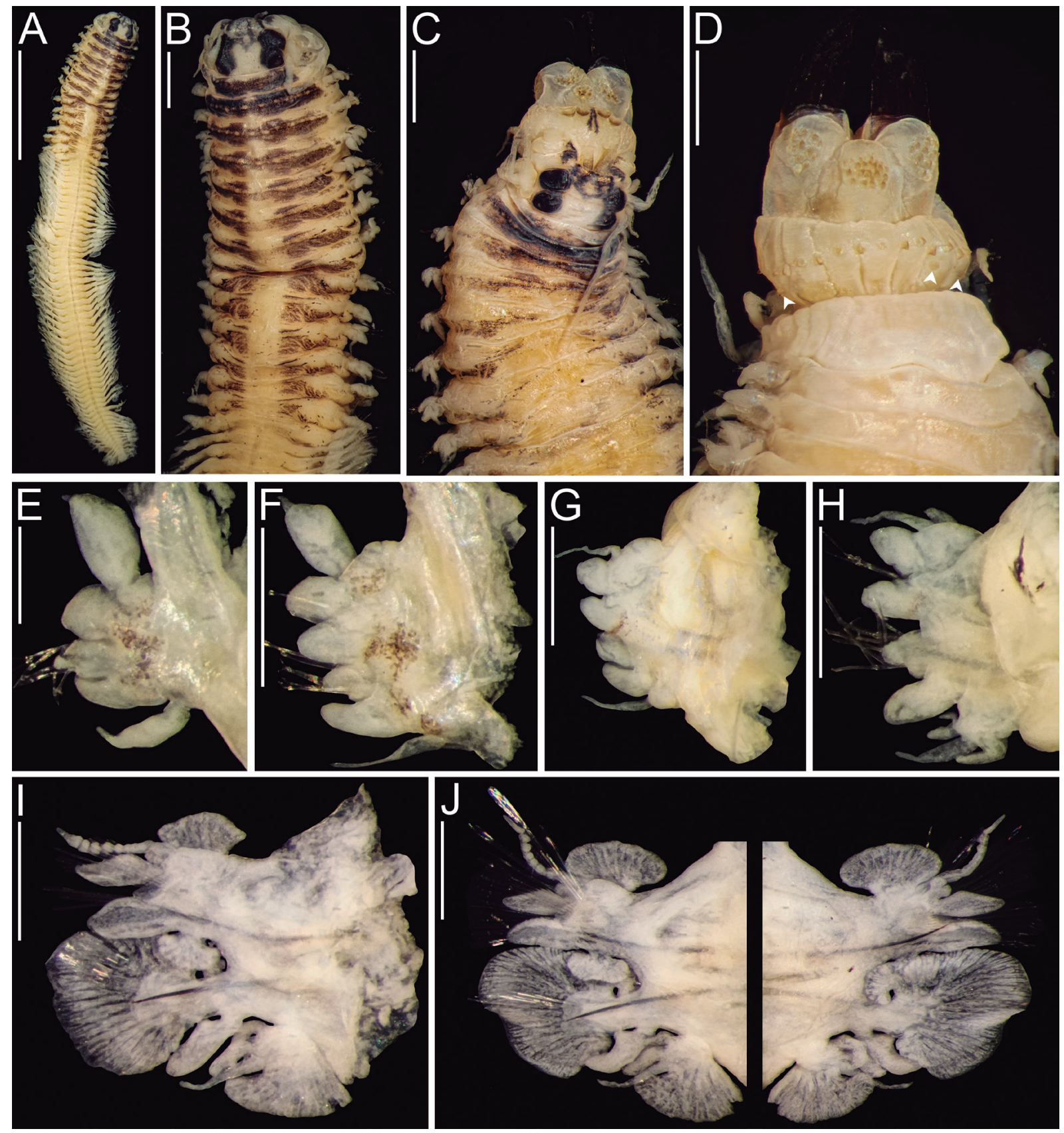

Fig. 12. Perinereis cariboea De León-González \& Solís-Weiss, 1998. Non-types (ECOSUR P3209). A. Whole specimen, dorsal view. B. Anterior end, dorsal view. C. Anterior end, dorsal view. D. Same, ventral view. E. Chaetiger 2, right parapodium. F. Chaetiger 6, right parapodium. G. Chaetiger 12, right parapodium. H. Chaetiger 14, right parapodium. I. Chaetiger 18, right parapodium. J. Chaetiger 35, right parapodium in anterior (left) and posterior (right) views. Scale bars: $\mathrm{A}=5 \mathrm{~mm} ; \mathrm{B}-\mathrm{D}=1 \mathrm{~mm} ; \mathrm{E}=$ $0.25 \mathrm{~mm} ; \mathrm{F}-\mathrm{J}=0.5 \mathrm{~mm}$. 
$1 \times$ in chaetiger $6,0.7 \times$ length in chaetiger $12($ Fig. $12 \mathrm{E}-\mathrm{G})$. Ventral cirrus pyriform in chaetigers $1-5$, filiform thereafter (Fig. 12E-G).

Natatory Region. Parapodia distinct from atokous ones (Fig. 12H-J). Dorsal cirrus filiform, crenulations present from chaetiger 15, decreasing in size and number toward posterior chaetigers until disappear (Fig. 12H-J); $1.8 \times$ as long as distal lobe of dorsal ligule in chaetiger $14,1.4 \times$ in chaetiger $18,1.7 \times$ in chaetiger 35 (Fig. 12H-J). Upper lamella of dorsal cirrus present since chaetiger 14, digitiform in chaetiger 14, flabellate thereafter, larger in middle chaetigers, as long as dorsal cirrus in chaetiger 35 (Fig. 12H-J); ventral lamella since chaetiger 14, flabellate and smaller than upper lamella of dorsal cirrus throughout (Fig. 12H-J). Dorsal ligule subconical in chaetiger 14, digitiform thereafter, becoming narrower toward posterior chaetigers (Fig. 12H-J); distal lobe of dorsal ligule $1 \times$ length of median ligule in chaetiger 14, $1.5 \times$ longer in chaetigers 18-35 (Fig. 12H-J). Notopodial prechaetal lobe rounded, lamelliform, present since chaetiger $15 ; 0.3 \times$ as long as dorsal ligule in chaetigers $18-35$ (Fig. 12H-J); small basal lamella of median ligule present since chaetiger 15, flabellate throughout (Fig. 12H-J). Neuroacicular ligule subconical in chaetiger 14, digitiform thereafter (Fig. 12H-J), superior and inferior lobes absent; $1 \times$ as long as ventral ligule in chaetiger $14,1.2 \times$ longer in chaetiger $18-35$ (Fig. 12H-J). Neuropodial postchaetal lobe rounded in chaetiger 14, transformed into broad flabellate ventral lamella with a basal, dorsal protrusion thereafter (Fig. 12H-J); $1.5 \times$ as long as neuroacicular ligule in chaetigers 18-35 (Fig. 12H-J). Ventral ligule digitiform and with small basal, dorsal lobe starting in chaetiger 15 (Fig. $12 \mathrm{H}-\mathrm{J}$ ); $0.7 \times$ as long as ventral cirrus in chaetiger $14,0.8 \times$ in chaetigers $18-35$ (Fig. 12H-J). Ventral cirrus filiform throughout (Fig. 12H-J); upper lamella divided in two subequal, digitiform lobes (Fig. 12H-J); lower lamella flabellate, $4-5 \times$ as wide as upper ones throughout (Fig. 12H-J).

ACICULAE. Basally amber and distally dark brown, amber region enlarges toward posterior chaetigers. Notoaciculae absent in first two chaetigers, proximal end rectangular in non-natatory region and becoming flabellate in natatory one.

Noto- AND NEUROCHAETAE. Resembling atokous ones in non-natatory region, replaced with paddle-like, heterogomph chaetae with short bosses in natatory region.

Pygidium. Crenulated, with a rosette of papillae formed by two or three rows of papillae; anal cirri missing (Fig. 12A).

\section{Remarks}

Perinereis cariboea has been scarcely recorded since its description; here is described its epitokal morphology, unknown until now. This species is easily identified among the species herein studied by its pharyngeal arrangement: no paragnaths in area V, two smooth bars on each area VI, and a discontinuous posterior band of paragnaths in areas VII-VIII. Atokes of $P$. cariboea are similar to P. bairdii because of the short tentacular cirri and the similar development of parapodia along the body. Regardless of the pharyngeal arrangement, the males of this species can be differentiated from males of $P$. bairdii as follows: 1) in P. cariboea, dorsal cirri are pyriform in chaetigers 6-7, whereas in P. bairdii they are cattail-like; 2$)$ in $P$. cariboea, ventral cirri are longer than ventral ligules in chaetigers $12-13$, whereas in P. bairdii they are shorter; 3) in P. cariboea, dorsal and ventral ligules are subequal in chaetiger 14, whereas in P. bairdii dorsal ligule is $2.7 \times$ as long as ventral one; 4 ) in $P$. cariboea, upper lamellae of dorsal cirri in natatory chaetigers are as long as dorsal cirri in chaetigers $30-35$, whereas in P. bairdii they are $0.7 \times$ the length; 5) in $P$. cariboea, ventral lamella is $1.5 \times$ as long as neuroacicular ligules in chaetiger 30 , whereas in $P$. bairdii they are $2.5 \times$ longer.

\section{Distribution}

Caribbean Sea. 


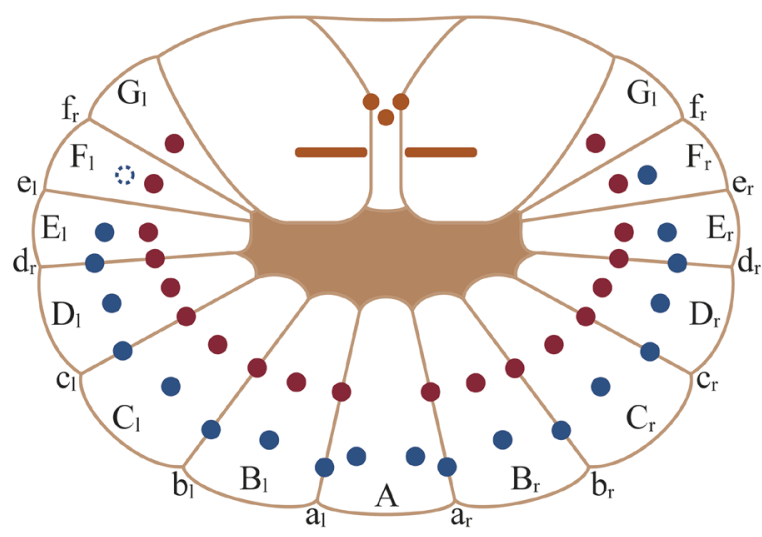

Perinereis anderssoni

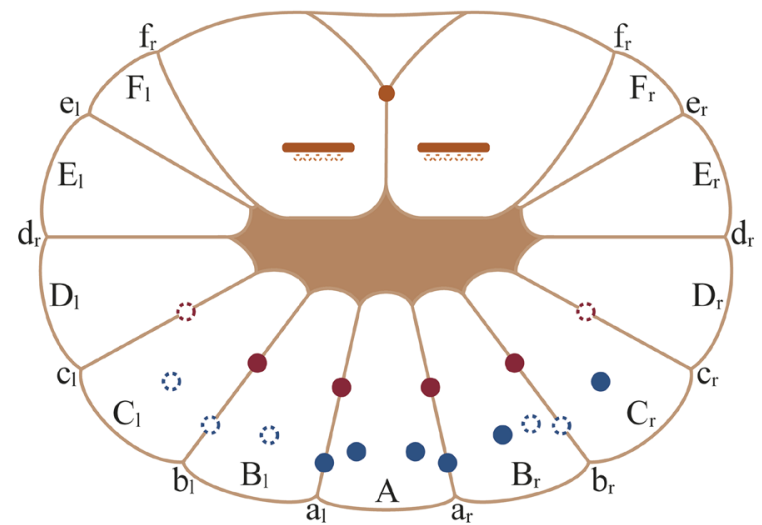

Perinereis websteri sp. nov.

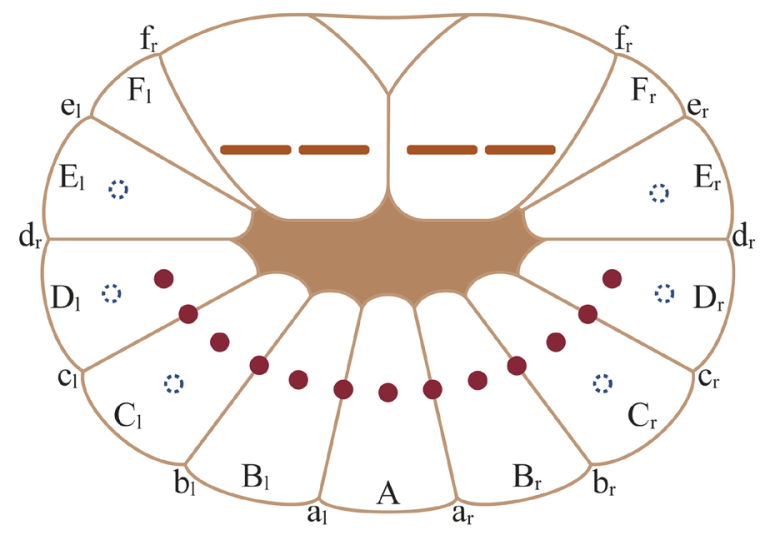

Perinereis cariboea

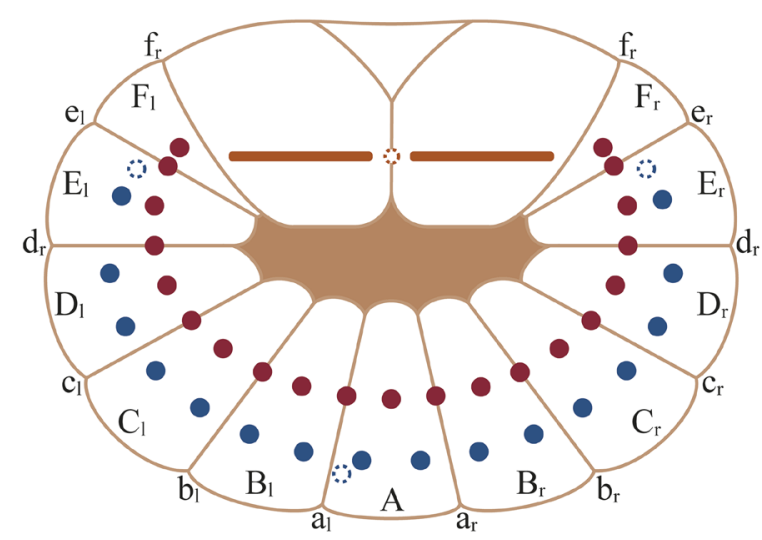

Perinereis bairdii

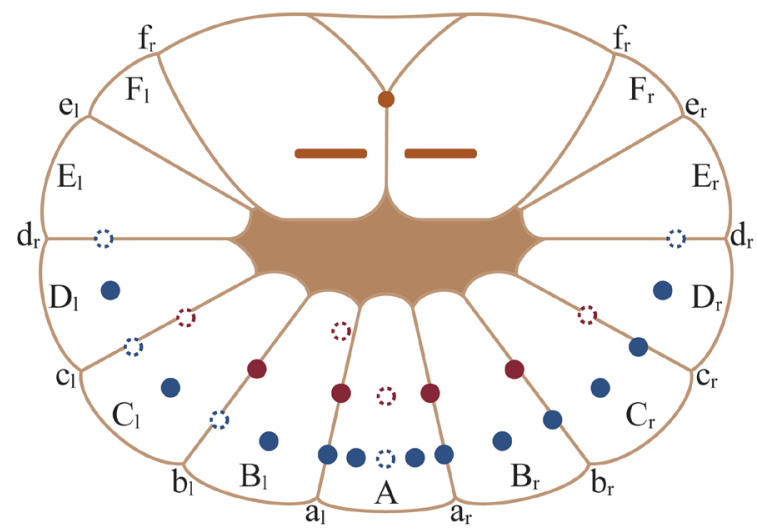

Perinereis floridana

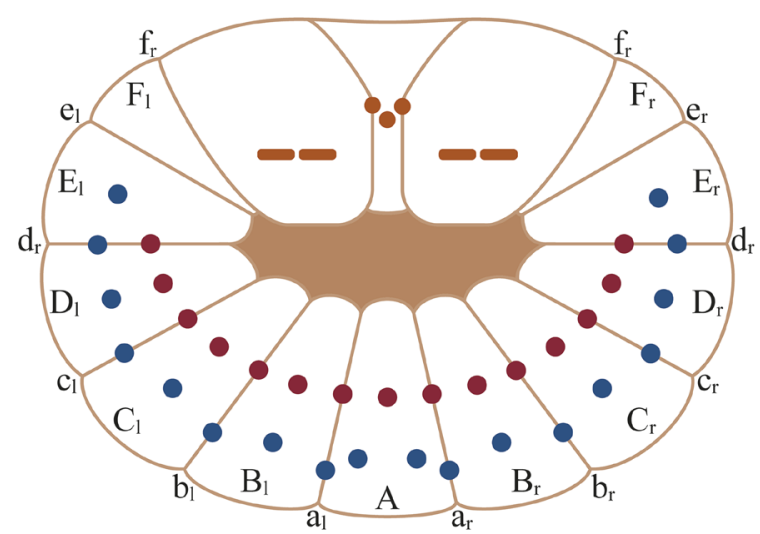

Perinereis rookeri

cones $\overline{\text { smooth bars }}$ broad-petite bars

Fig. 13. Arrangement of paragnaths in the ridge and furrow regions of areas VII-VIII in species of Perinereis Kinberg, 1865. Filled figures with solid edges represent paragnaths observed in all specimens examined, no-filled figures with dashed edges represent paragnaths observed in some specimens only. 


\section{Key to Atlantic Perinereis species (excluding the Mediterranean Sea) ${ }^{1,4}$}

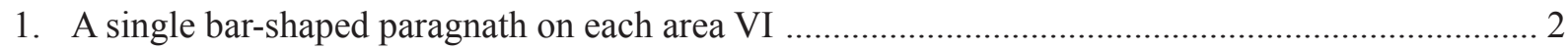

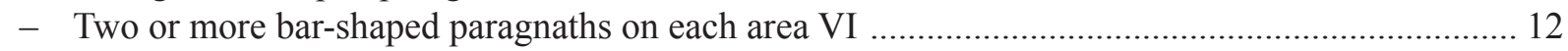

2. Lacking paragnaths in area V .......P. capensis (Kinberg, 1865) (Cape of Good Hope, South Africa)

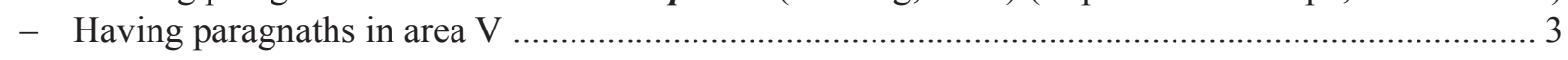

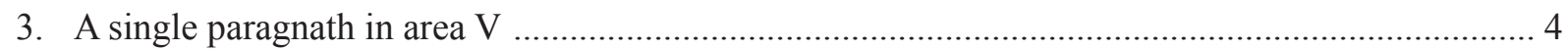

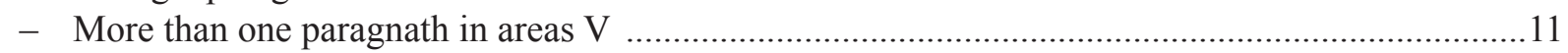

4. Tentacular cirri extending back up to chaetiger 4 (i.e., short tentacular cirri) ................................. 5

- Tentacular cirri extending back beyond chaetiger 6 (i.e., long tentacular cirri) .............................. 9

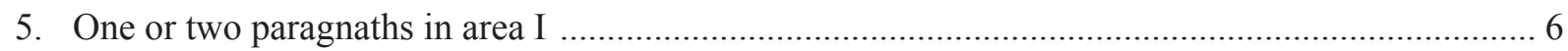

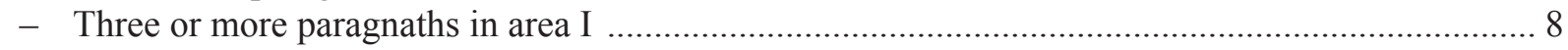

6. Areas VII-VIII with a single broad band with several rows of paragnaths ( $>100$ paragnaths) .........

..P. falklandica (Ramsay, 1914) (Falkland Islands)

- Areas VII-VIII with 3-4 rows of paragnaths (about 19-43 paragnaths) ........................................ 7

7. Paragnath in area $\mathrm{V}$ aligned with bars in areas VI, forming a straight row; each bar in areas VI almost as long as wide as area VI (i.e., long bars) ................................ oliveirae (Horst, 1889) (Portugal)

- Paragnath in area V displaced backward, not aligned with bars in areas VI; each bar in areas VI up to half as long as wide as area VI (i.e., short bars) ...............P. atlantica (São Vicente, Cape Verde)

8. Dorsal ligules $2.3 \times$ as long as median ligules and ventral ligules shorter than neuroacicular ligules in posterior chaetigers

..P. ponteni Kinberg, 1865 (Rio de Janeiro, Brazil)

- Dorsal ligules $3.3 \times$ as long as median ligules and ventral ligules longer than neuroacicular ligules in posterior chaetigers .P. bairdii (Webster, 1884) (Bermuda)

9. Dorsal cirri subequal or shorter than distal lobes of dorsal ligules and ventral ligules longer than neuroacicular ligules in posterior chaetigers

P. floridana (Ehlers, 1868) (Captiva Key, Florida, USA)

- Dorsal cirri longer than distal lobes of dorsal ligules and ventral ligules shorter than neuroacicular ligules in posterior chaetigers

10. A single paragnath in area I; ventral cirri shorter than ventral ligules in posterior chaetigers

P. falsovariegata Monro, 1933a (Preekstoel, South Africa)

- Three or more paragnaths in area I; ventral cirri longer than ventral ligules in posterior chaetigers .

.. P. websteri sp. nov. (Bermuda)

11. Two bands of paragnaths in areas VII-VIII; dorsal ligules several times longer than median ligules in posterior chaetigers .P. anderssoni Kinberg, 1865 (Rio de Janeiro, Brazil)

- A single band of paragnaths in areas VII-VIII; both dorsal and median ligules subequal in posterior chaetigers ..........................................Perinereis taorica Langerhans, 1881 (Canary Islands, Spain)

12. Nine to ten bar-shaped paragnaths on each area VI

P. latipalpa (Schmarda, 1861) (Cape of Good Hope, South Africa)

- Two bar-shaped paragnaths on each area VI 13 
13. Paragnaths absent in area V; posterior band of paragnaths in areas VII-VIII discontinuous

P. cariboea de León-González \& Solís-Weiss, 1998 (Quintana Roo, Mexico)

- Paragnaths absent in area V; posterior band of paragnaths in areas VII-VIII continuous ............. 14

14. Notopodial prechaetal lobes present at least in anterior chaetigers; rows in areas VII-VIII with paragnaths of distinct size

P. brevicirrata (Treadwell, 1920) (Brazil) ${ }^{2}$

- Notopodial prechaetal lobe absent; rows in areas VII-VIII with paragnaths of similar size ......... 15

15. Distal lobes of dorsal ligules subequal or shorter than medial ligules in posterior chaetigers; blades of neuropodial falcigers with rod-like tips

P. rookeri de León-González \& Goethel, 2013 (Rookery Bay, Florida, USA)

- Distal lobes of dorsal ligules longer than medial ligules in posterior chaetigers; blades of neuropodial falcigers with falcate tips ..........P. mochimaensis Liñero-Arana, 1983 (Mochima Bay, Venezuela) / .P. cariacoensis Liñero-Arana, 1983 (Golfo de Cariaco, Venezuela) ${ }^{3}$

${ }^{1}$ Nereis marionii Audouin \& Milne Edwards, 1833 (type locality: Vendée, France) (synonyms: P. longipes de Saint-Joseph, 1898 from Guettary, France, and Nereis crassipes de Quatrefages, 1866 from Normandy, France) and N. aculeata Hansen, 1882 (type locality: Brazil) are excluded from the key. Nereis marionii differs in several pharyngeal and parapodial features from Perinereis species, such as having a continuous band of paragnaths in the oral ring, and the presence of notopodial prechaetal lobes and additional upper lobe in dorsal ligules (Audouin \& Milne-Edwards 1833; Fauvel 1923), so likely it belongs to a distinct genus. The original description of Nereis aculeata is succinct (Hansen 1882) and allows to identify it as a Perinereis, but further study is needed to determine if it is a valid species.

${ }^{2}$ Treadwell (1920: fig. 2) described a parapodium from chaetiger 10 (likely depicted upside down in his figure) with three notopodial ligules. The species needs further re-evaluation to ensure it is a Perinereis species.

${ }^{3}$ As pointed out by de León-González \& Goethel (2013), both species are very similar. Both species were proposed based on a single specimen each (even one of them incomplete), and differences in head and parapodial morphology between them are very subtle. Chances are that the transverse bar in area $\mathrm{V}$ is due to the partial merging of two or more conical paragnaths like in melted paragnaths, which have been observed in some specimens of $P$. websteri sp. nov. in additional paragnaths in areas VI. A revision of the type and additional material of both species is needed to clarify their validity.

${ }^{4}$ References consulted: Horst (1889); Treadwell (1920); Monro (1933a); Hartman (1938b); Day (1967); Liñero-Arana (1983); de León-González \& Solís-Weiss (1998); Núñez (2004); de León-González \& Goethel (2013); Darbyshire (2014); Coutinho et al. (2015); Paiva et al. (2018); Villalobos-Guerrero (2019).

\section{Discussion}

\section{The morphological distinction between Perinereis sympatric species}

Currently, there are about 89 Perinereis species accepted (Villalobos-Guerrero et al. 2021), and some of them are sympatric with high a morphological similarity. For example, Glasby \& Hsieh (2006) studied the morphology of Perinereis nuntia species complex from Taiwan and neighboring waters, and found the occurrence of $P$. mictodonta (von Marenzeller, 1879), P. nuntia (Savigny in Lamarck, 1818), and P. rhombodonta (Wu, Sun \& Yang, 1981) as well as of three unknown and identified as new species, P. shikueii Glasby \& Hsieh, 2006, P. viridis Glasby \& Hsieh, 2006 and P. wilsoni Glasby \& Hsieh, 2006. Later, Tosuji et al. (2019) recorded the presence of P. mictodonta, P. wilsoni, P. shikueii, and P. nuntia 
from Japan using both morphological and molecular data, and found that $P$. shikueii showed cryptic speciation. Another example is the distinction between $P$. anderssoni and P. ponteni Kinberg, 1865, both proposed from Rio de Janeiro and previously regarded as synonyms, but Coutinho et al. (2015) clarified the morphological differences among them through a morphometric analysis using material from several localities, and later Paiva et al. (2018) found differences with molecular data, reinforcing the idea they are distinct species. In all these cited works, the relevant morphological features for separating between species were the number of paragnaths and their arrangement in the pharynx (especially areas V and VI), and the relative size of dorsal cirri and dorsal ligules along the body.

Here, these features were also useful to differentiate the close species $P$. anderssoni and P. bairdii, and the sympatric species $P$. bairdii and $P$. websteri sp. nov. As highlighted above, the number of paragnaths and their arrangement and the parapodial morphology between $P$. anderssoni and P. bairdii as well as between $P$. websteri sp. nov. and $P$. floridana are similar. Two key features, the length of the tentacular cirri and the relative size of the dorsal ligules along the body, were obvious to recognize distinct morphological patterns among specimens of the same lot. Once they were grouped (short/ long tentacular cirri and small/large dorsal ligule), a detailed study of pharynx and parapodia showed slight but consistent differences among the specimens. The determination of the pattern in areas $\mathrm{V}-$ VI-V also was useful and consistent across the specimens of a same species, adding an extra feature to separate $P$. anderssoni (П-shaped) and $P$. websteri sp. nov. ( $\lambda$-shaped). Perinereis rookeri de LeónGonzález \& Goethel, 2013 has a similar pharyngeal arrangement in the oral ring (Fig. 13), but they can be easily separated by the number and kind of bars in areas VI, the relative size of dorsal cirri, the dorsal ligules along the body, and the shape of blades of neuropodial falcigers (de León-González \& Goethel 2013).

The improvement of the ridge and furrow system to not only determine the number of bands and rows and their position in the midventral region as originally stated but also to describe the position of paragnaths in all oral regions as herein proposed, demonstrates the arrangement of paragnaths to differ among the six species herein studied. Also, it allowed revealing that $P$. anderssoni has a different number of ridge and furrow regions than P. bairdii, P. websteri sp. nov. and P. cariboea (Fig. 13), having the ridge region G. The question if the pharynx depicted by Webster was of the same or another specimen, and useful in the splitting of the syntypes of $N$. bairdii, is clearly answered after the use of this system. The number of paragnaths in areas VII-VIII in P. anderssoni ranges from 40 to 44 in the specimens examined and from 33 to $39 \mathrm{in} P$. bairdii, which is explained by adding a single ridge region found to bear new paragnaths. This idea is reinforced after our examination by the fact that the number of paragnaths found on each furrow and ridge region is almost constant in the same species. Perinereis anderssoni has 2 paragnaths on the regions $\mathrm{B}-\mathrm{F}$ and $\mathrm{a}-\mathrm{d}$, with 38 paragnaths in total, while $P$. bairdii has 3 paragnaths on each of the regions $\mathrm{B}-\mathrm{E}$, and a single paragnath on each region $\mathrm{F}$, and 1 paragnath on the regions c-e, with 36 paragnaths in total, so the larger number of paragnaths in $P$. anderssoni is explained by the presence of the extra region G. This means that the more regions are available, the more paragnaths the areas VII-VIII can hold. This regular pattern in the number of paragnaths in the ridge and furrow regions is also observed in Pseudonereis species such as P. brunnea, P. citrina, P. fauveli, P. gallapagensis, P. palpata, and P. variegata (Conde-Vela, 2018; pers. obs.). These findings suggest that adjacent furrow and ridge regions and their number of paragnaths are very similar to each other, existing in a single pattern that repeats itself several times along the areas VII-VIII. Future studies will address this issue covering more species and genera.

After the examination of atokes and epitokes of P. bairdii, P. floridana, and P. cariboea, it is evident that the anterior chaetigers of the atokes and chaetigers from the pre-natatory region of the epitokes slightly differ, especially because the parapodia from the pre-natatory region are swollen because the chaetigers are filled with gametes, giving a more rounded appearance and slightly modifying the size of 
the ligules. Linking the atoke and epitoke morphology with this limitation was possible using the length of the tentacular cirri, the pharyngeal arrangement. The parapodial proportions are most conservative in notopodial structures in the pre-natatory region only, whereas the neuroacicular ligules and ventral ligules differ markedly. In the pre-natatory region of epitokes of Perinereis bairdii, P. floridana, and $P$. cariboea, the neuroacicular ligules were the most diverging, becoming much shorter than in their atokes counterparts.

The epitoke morphology among Perinereis species studied is very similar in the pre-natatory regions, where the main difference is in the shape of the dorsal cirri in the chaetigers 6-7. Interestingly, in males of P. floridana and P. cariboea, the tentacular cirri are long, i.e., reaching back beyond chaetiger 5, and share a short number of pre-natatory chaetigers (13), whereas in $P$. bairdii the tentacular cirri are short, i.e., reaching back up to chaetigers $2-3$, and they have more pre-natatory chaetigers (17). Other species with males having long tentacular cirri such as P. aibuhitensis (Grube, 1878), P. linea (Treadwell, 1936), P. mictodonta (von Marenzeller, 1879), P. weijhouensis Wu, Sun \& Yang, 1981, and P. wilsoni Glasby \& Hsieh, 2006, have more pre-natatory regions $(21,19,16,25$, and 16, respectively), whereas in species with short tentacular cirri such as $P$. anderssoni, P. barbara, P. nigropunctata (Horst, 1889), P. obfuscata (Grube, 1878), and P. suluana (Horst, 1924), have less pre-natatory chaetigers $(14,13,15$ or 14, 13 or 14, and 14, respectively) (Wu et al. 1985; Hutchings et al. 1991; Glasby \& Hsieh 2006; Pamungkas \& Glasby 2015; Peixoto \& Santos 2016). An exception is P. helleri with short tentacular cirri (3) and several pre-natatory chaetigers (17) (Pamungkas \& Glasby 2015). Future studies could address if this trend is constant in more species and if other morphological features allow to group them.

\section{Conclusions}

Perinereis anderssoni is redescribed based on topotype specimens and found to be restricted to the Brazilian coasts, the junior synonyms Nereis bairdii and Nereis (Perinereis) melanocephala are rejected. The syntypes of Nereis bairdii were examined and specimens with two distinct morphological patterns were found, so the syntypes were divided: some specimens were designated as the lectotypes and paralectotypes of $N$. bairdii and the species Perinereis bairdii was reinstated, and the remaining ones were identified as the new species Perinereis websteri sp. nov. Nereis (Perinereis) melanocephala is regarded as a junior synonym of $P$. websteri sp. nov. The use of pharyngeal features such as the shape of areas V-VI-V and the arrangement of paragnaths in furrow and ridge regions in areas VII-VIII, added additional evidence to separate Perinereis anderssoni, P. bairdii, and P. websteri sp. nov. The Perinereis species herein studied also have differences in their reproductive morphology in the shape and size of the structures only and not in their main pattern. The slight changes in the shape and size of parapodial lobes in the pre-natatory region in epitokes are attributed to the accumulation of gametes in the parapodia.

\section{Acknowledgments}

The author thanks the kind support from the following curators and collections managers: Adam Baldinger (MCZ), Geoff Keel (USNM), Gonzalo Giribet (MCZ), Jennifer Winifred Lenihan (MCZ), Karen Osborn (USNM), Kathryn Ahlfeld (USNM), Kirk Fitzhugh (LACM), Leslie Harris (LACM), and William Moser (USNM). I am thankful to Alexandra Rizzo (UERJ) and Cinthya Santos (IBUFRJ) for sending additional specimens for this study. The author thanks Sergio I. Salazar-Vallejo and Luis F. Carrera-Parra for the support provided in their research laboratory. I am also grateful for the careful reviews provided by the referees Robin Wilson and Torkild Bakken. This work was supported by a scholarship from CONACyT (586685) and currently by a postdoctoral grant from the same institution; the Smithsonian Institution under the Kenneth Jay Boss Fellowship in Invertebrate Zoology (2018) and the Museum of Comparative Zoology under the Ernst Mayr Travel Grant (2019). 


\section{References}

Andrew W. \& Andrew N.V. 1953. Some annelid and sipunculid worms of the Bimini region. American Museum Novitates 1617: 1-16. Available from http://hdl.handle.net/2246/4869 [accessed 25 Nov. 2021].

Audouin J.V. \& Milne-Edwards H. 1833. Classification des Annélides, et description de celles qui habitent les côtes de la France (Suite 1). Annales des Sciences Naturelles (Zoologie) Série 8 29: 195269. Available from https://www.biodiversitylibrary.org/page/6044727 [accessed 17 Dic. 2021].

Augener H. 1922. Litorale Polychaeten von Juan Fernandez. In: Skottsberg C. (ed.) The Natural History of Juan Fernandez and Easter Island 3: 161-218. Almqvist \& Wiksells Boktryckeri. Uppsala. https://doi.org/10.5962/bhl.title.41367

Augener H. 1927. Polychaeten von Curaçao. Bijdragen tot de Dierkunde 25 (1): 39-82. https://doi.org/10.1163/26660644-02501003

Augener H. 1934. Polychaeten aus den zoologischen Museen von Leiden und Amsterdam. IV (Schluss). Zoologische Mededeelingen 17 (8): 67-160. Available from https://repository.naturalis.n1/pub/318471 [accessed 25 Nov. 2021].

Augener H. 1936. Polychaeten aus den marinen Salinen von Bonaire und Curaçao. Zoologische Jahrbücher, Abteilung für Systematik, Ökologie und Geographie der Tiere 67 (5-6): 337-352.

Bakken T. \& Wilson R.S. 2005. Phylogeny of nereidids (Polychaeta, Nereididae) with paragnaths. Zoologica Scripta 34 (5): 507-547. https://doi.org/10.1111/j.1463-6409.2005.00200.x

Conde-Vela V.M. 2018. New species of Pseudonereis Kinberg, 1865 (Polychaeta: Nereididae) from the Atlantic Ocean, and a review of paragnath morphology and methodology. Zootaxa 4471 (2): 245-278. https://doi.org/10.11646/zootaxa.4471.2.2

Conde-Vela V.M. 2021. Revision of Laeonereis Hartman, 1945 (Annelida: Phyllodocida: Gymnonereidinae), with a review of shaft morphology in nereidids. Journal of Natural History 55 (78): 381-455. https://doi.org/10.1080/00222933.2021.1903601

Conde-Vela V.M., Wu X. \& Salazar-Vallejo S.I. 2018. Reevaluation and new species of Kainonereis Chamberlin, 1919 (Annelida: Polychaeta: Nereididae). Zoological Studies 57: 1-24.

https://doi.org/10.6620/ZS.2018.57-06

Coutinho M.C.L. \& Santos C.S.G. 2014. Morphological anomalies in polychaetes: Perinereis species (Polychaeta: Annelida) examples from the Brazilian coast. Memoirs of Museum Victoria 71: 45-51. https://doi.org/10.24199/j.mmv.2014.71.05

Coutinho M.C.L., Paiva P.C. \& Santos C.S.G. 2015. Morphometric analysis of two sympatric species of Perinereis (Annelida: Nereididae) from the Brazilian coast. Journal of the Marine Biological Association of the United Kingdom 95 (5): 1-7. https://doi.org/10.1017/S0025315415000247

Darbyshire T. 2014. Intertidal and nearshore Nereididae (Annelida) of the Falkland Islands, southwestern Atlantic, including a new species of Gymnonereis. ZooKeys 427: 75-108.

https://doi.org/10.3897/zookeys.427.7296

Day J.H. 1967. A Monograph on the Polychaeta of Southern Africa. Part I. Errantia. Trustees of the British Museum (Natural History), London. https://doi.org/10.5962/bhl.title.8596

de León-González J.A. \& Goethel C.A. 2013. A new species of Perinereis (Polychaeta, Nereididae) from Florida, USA, with a key to all Perinereis from the American continent. ZooKeys 312: 1-11. https://doi.org/10.3897/zookeys.312.4535

de León-González J.A. \& Solís-Weiss V. 1998. The genus Perinereis (Polychaeta: Nereididae) from Mexican littoral waters, including the description of three new species and the redescriptions of 
P. anderssoni and P. elenacasoae. Proceedings of the Biological Society of Washington 111 (3): 674693. Available from https://www.biodiversitylibrary.org/page/34597849 [accessed 25 Nov. 2021].

Dean H.K. 2012. A literature review of the Polychaeta of the Caribbean Sea. Zootaxa 3596 (1): 1-86. https://doi.org/10.11646/zootaxa.3596.1.1

Díaz-Díaz Ó.F. \& Liñero-Arana I. 2002. Poliquetos asociados a substratos artificiales sumergidos en la costa nororiental de Venezuela IV. Phyllodocida (Annelida: Polychaeta). Boletín del Instituto Oceanográfico de Venezuela 41: 25-37.

Ehlers E. 1868. Die Borstenwürmer (Annelida Chaetopoda) nach systematischen und anatomischen Untersuchungen. Erster Band. Wilhelm Engelmann, Leipzig. https://doi.org/10.5962/bhl.title.2081

Fauchald K. 1977. Polychaetes from intertidal areas in Panama, with a review of previous shallow-water records. Smithsonian Contributions to Zoology 221: 1-81. https://doi.org/10.5479/si.00810282.221

Fauvel P. 1923. Polychètes Errantes. Faune de France 5: 1-488.

Glasby C.J. \& Hsieh H.-L. 2006. New species and new records of the Perinereis nuntia species group (Nereididae: Polychaeta) from Taiwan and other Indo-West Pacific shores. Zoological Studies 45 (4): $553-577$.

Hansen G.A. 1882. Recherches sur les Annélides Recueillies par M. le professeur Édouard Van Beneden pendant son voyage au Brésil et à La Plata. Mémoires couronnés et Mémoires des Savants étrangers publiés par l'Académie royale des Sciences, des Lettres et des Beaux-Arts de Belgique 44 (3): 1-29. Available from https://www.biodiversitylibrary.org/page/5943290 [accessed 25 Nov. 2021].

Hartman O. 1938a. Annotated list of the types of polychaetous annelids in the Museum of Comparative Zoology. Bulletin of the Museum of Comparative Zoology at Harvard College 85 (1): 1-31. Available from https://www.biodiversitylibrary.org/page/4537955 [accessed 25 Nov. 2021].

Hartman O. 1938b. Nomenclatorial changes involving types of polychaetous annelids of the family Nereidae in the United States National Museum. Journal of the Washington Academy of Sciences 28 (1): 13-15. Available from https://www.biodiversitylibrary.org/page/39690754 [accessed 25 Nov. 2021].

Hartman O. 1944. Polychaetous Annelids. Allan Hancock Atlantic Expedition 3: 1-33. Available from https://www.biodiversitylibrary.org/page/4678548 [accessed 25 Nov. 2021].

Hartman O. 1948. The marine annelids erected by Kinberg with notes on some other types in the Swedish State Museum. Arkiv för Zoologi 42A (1): 1-137.

Hartman O. 1951. The littoral marine annelids of the Gulf of Mexico. Publications of the Institute of Marine Science 2 (1): 7-124. Available from http://hdl.handle.net/2152/22162 [accessed 25 Nov. 2021].

Hoagland R.A. 1919. Polychaetous annelids from Porto Rico, the Florida Keys, and Bermuda. Bulletin of the American Museum of Natural History 41: 571-591.

Horst R. 1889. Contribution towards the knowlegde of the Annelida Polychaeta. On species of Nereis, belonging to the sub-genus Perinereis. Notes from the Leyden Museum 11: 161-186.

Horst R. 1924. Polychaeta Errantia of the Siboga-Expedition. Pt. 3. Nereidae and Hesionidae. SibogaExpeditie Monographs 24 (1c): 145-198.

Hutchings P.A., Reid A. \& Wilson R.S. 1991. Perinereis (Polychaeta, Nereididae) from Australia, with redescriptions of six additional species. Records of the Australian Museum 43 (3): 241-274.

https://doi.org/10.3853/j.0067-1975.43.1991.47

Ibárzabal D.R. 1986. Poliquetos de Punta Este, Isla de la Juventud. I. Familias Nereidae, Glyceridae, y Goniadidae. Poeyana 309: 1-16. 
ICZN. 1999. International Code of Zoological Nomenclature. $4^{\text {th }}$ Ed. International Trust for Zoological Nomenclature (The Natural History Museum), London. Available from https://www.iczn.org/the-code/the-code-online/ [accessed 17 Dic. 2021].

Kinberg J.G.H. 1865. Annulata Nova (Nereidum Dispositio Nova. Leonnatidea, Nereidea, Aretidea, Pisenoidea, Niconidea). Öfversigt af Kongelige Vetenskaps-Akademiens Förhandlingar 22 (2): 167179. Available from https://www.biodiversitylibrary.org/page/32339443 [accessed 25 Nov. 2021].

Langerhans P. 1880. Die Wurmfauna Madeiras. II. Zeitschrift für Wissenschaftliche Zoologie 33: 271316. Available from https://www.biodiversitylibrary.org/page/45632728 [accessed 25 Nov. 2021].

Liñero-Arana I. 1983. Dos nuevas especies de Nereidae (Polychaeta: Errantia) de la costa oriental de Venezuela. Boletín del Instituto Oceanográfico de Venezuela 22 (1-2): 3-6.

Liñero-Arana I. \& Reyes-Vásquez G. 1979. Nereidae (Polychaeta, Errantia) del Golfo de Cariaco, Venezuela. Boletín del Instituto Oceanográfico de la Universidad de Oriente 18 (1-2): 3-12.

McIntosh W.C. 1885. Report on the Annelida Polychaeta dredged by H.M.S. Challenger during the years 1873-1876. Report on the Scientific Results of the Voyage of H.M.S. Challenger during the Years 1873-1876. Zoology 12: 1-554. Available from https://doi.org/10.5962/bhl.title.6513 [accessed 25 Nov. 2021].

Monro C.C.A. 1933a. Notes on a collection of Polychæta from South Africa. Journal of Natural History 11 (64): 487-509. https://doi.org/10.1080/00222933308673679

Monro C.C.A. 1933b. The Polychaeta Errantia collected by Dr. C. Crossland at Colón, in the Panama Region, and the Galapagos Islands during the expedition of the S.Y. 'St. George'. Proceedings of the Zoological Society of London 103 (1): 1-96. https://doi.org/10.1111/j.1096-3642.1933.tb01578.x

Monro C.C.A. 1933c. On a collection of Polychaeta from Dry Tortugas, Florida. Annals and Magazine of Natural History, Series 1012 (69): 244-269. https://doi.org/10.1080/00222933308655413

Núñez J. 2004. Familia Nereididae. In: Viéitez J.M., Alós C., Parapar J., Besteiro C., Moreira J., Núñez J., Laborda J. \& San Martín G. Annelida Polychaeta I. Ramos M.Á. et al. (eds) Fauna Iberica 25: 293-390. Museo Nacional de Ciencias Naturales, CSIC, Madrid.

Paiva P.C., Mutaquilha B.F., Coutinho M.C.L. \& Santos C.S.G. 2018. Comparative phylogeography of two coastal species of Perinereis Kinberg, 1865 (Annelida, Polychaeta) in the South Atlantic. Marine Biodiversity 49 (3): 1537-1551. https://doi.org/10.1007/s12526-018-0927-0

Pamungkas J. \& Glasby C.J. 2015. Taxonomy of reproductive Nereididae (Annelida) in multispecies swarms at Ambon Island, Indonesia. ZooKeys 520: 1-25.

https://doi.org/https://doi.org/10.3897/zookeys.520.9581

Peixoto A.J.M. \& Santos C.S.G. 2016. Reproductive biology of Perinereis anderssoni (Polychaeta: Nereididae) in a subtropical Atlantic Beach. Invertebrate Reproduction \& Development 60 (3): 201-211. https://doi.org/10.1080/07924259.2016.1194333

Rioja E. 1960. Estudios anelidológicos. XXIV. Adiciones a la fauna de anélidos poliquetos de las costas orientales de México. Anales del Instituto de Biología, Universidad Nacional Autónoma de México 31: 289-316.

Salazar-Vallejo S.I. 1996. Lista de especies y bibliografía de poliquetos (Polychaeta) del Gran Caribe. Anales del Instituto de Biología, Universidad Nacional Autónoma de México 67 (1): 11-50.

Salazar-Vallejo S.I. \& Jiménez-Cueto M.S. 1997. Neréididos (Polychaeta) del Caribe mexicano con una clave para las especies del Gran Caribe. Revista de Biología Tropical 44 (45): 361-377. 
Santos C.S.G. 2007. Nereididae from Rocas Atoll (North-East, Brazil). Arquivos do Museu Nacional do Rio de Janeiro 65 (3): 369-380.

Tosuji H., Nishinosono K., Hsieh H.-L., Glasby C.J., Sakaguchi T. \& Sato M. 2019. Molecular evidence of cryptic species diversity in the Perinereis nuntia species group (Annelida: Nereididae) with first records of P. nuntia and P. shikueii in southern Japan. Plankton and Benthos Research 14 (4): 287-302. https://doi.org/10.3800/pbr.14.287

Treadwell A.L. 1901. The polychaetous annelids of Porto Rico. Bulletin of the United States National Fish Commission 20 (2): 181-210.

Treadwell A.L. 1920. A new polychaetous annelid of the genus Nereis from Brazil. Proceedings of the United States National Museum 58: 567-468. https://doi.org/10.5479/si.00963801.58-2347.467

Treadwell A.L. 1939. Polychaetous annelids of Porto Rico and vicinity. Scientific Survey of Porto Rico and the Virgin Islands 16 (2): 1-319.

Vanegas-Espinosa V., Díaz-Díaz Ó.F. \& Liñero-Arana I. 2007. Nereididae Lamarck, 1818 (Annelida: Polychaeta) de la Costa Occidental de Venezuela. Boletín del Instituto Oceanográfico de Venezuela 46 (2): 119-127.

Villalobos-Guerrero T.F. 2019. Redescription of two overlooked species of the Perinereis nuntia complex and morphological delimitation of P. nuntia (Savigny in Lamarck, 1818) from the Red Sea (Annelida, Nereididae). Zoosystema 41 (24): 465-496.

https://doi.org/10.5252/zoosystema2019v41a24

Villalobos-Guerrero T.F. \& Bakken T. 2018. Revision of the Alitta virens species complex (Annelida: Nereididae) from the North Pacific Ocean. Zootaxa 4483 (2): 201-257.

https://doi.org/10.11646/zootaxa.4483.2.1

Villalobos-Guerrero T.F., Park T.S. \& Idris I. 2021. Review of some Perinereis Kinberg, 1865 (Annelida: Nereididae) species of Group 2 sensu Hutchings, Reid \& Wilson, 1991 from the Eastern and Southeastern Asian seas. Journal of the Marine Biological Association of the United Kingdom 101 (2): 279307. https://doi.org/10.1017/S0025315421000126

Webster H.E. 1884. Annelida from Bermuda, collected by G. Brown Goode. Bulletin of the United States National Museum 25: 305-327. Available from https://www.biodiversitylibrary.org/page/7725366 [accessed 25 Nov. 2021].

Wesenberg-Lund E. 1949. Polychætes from the Iranian Gulf. Danish Scientific Investigations in Iran 4: 247-400.

Wu B.-L., Sun R. \& Yang D.J. 1985. Nereidae (Polychaetous Annelids) of the Chinese Coast. China Ocean Press, Beijing.

Yousefi S., Rahimian H., Nabavi S.M.B. \& Glasby C.J. 2011. Nereididae (Annelida: Polychaeta) from intertidal habitats in the Gulf of Oman, Iran. Zootaxa 3013 (3): 48-64.

https://doi.org/10.11646/zootaxa.3636.3.8

Manuscript received: 27 August 2021

Manuscript accepted: 26 October 2021

Published on: 6 January 2022

Topic editor: Tony Robillard

Desk editor: Pepe Fernández 
Printed versions of all papers are also deposited in the libraries of the institutes that are members of the EJT consortium: Muséum national d'histoire naturelle, Paris, France; Meise Botanic Garden, Belgium; Royal Museum for Central Africa, Tervuren, Belgium; Royal Belgian Institute of Natural Sciences, Brussels, Belgium; Natural History Museum of Denmark, Copenhagen, Denmark; Naturalis Biodiversity Center, Leiden, the Netherlands; Museo Nacional de Ciencias Naturales-CSIC, Madrid, Spain; Real Jardín Botánico de Madrid CSIC, Spain; Zoological Research Museum Alexander Koenig, Bonn, Germany; National Museum, Prague, Czech Republic. 